\title{
Augmenting the eye of the beholder: exploring the strategic potential of augmented reality to enhance online service experiences
}

\author{
Tim Hilken ${ }^{1}$ (D) $\cdot$ Ko de Ruyter $^{2} \cdot$ Mathew Chylinski $^{3} \cdot$ Dominik Mahr $^{1,4}$. \\ Debbie I. Keeling ${ }^{5}$
}

Received: 30 June 2016 / Accepted: 21 April 2017 / Published online: 18 May 2017

(C) The Author(s) 2017. This article is an open access publication

\begin{abstract}
Driven by the proliferation of augmented reality (AR) technologies, many firms are pursuing a strategy of service augmentation to enhance customers' online service experiences. Drawing on situated cognition theory, the authors show that AR-based service augmentation enhances customer value perceptions by simultaneously providing simulated physical control and environmental embedding. The resulting authentic situated experience, manifested in a feeling of spatial presence, functions as a mediator and also predicts customer decision comfort. Furthermore, the effect of spatial
\end{abstract}

Tim Hilken

t.hilken@maastrichtuniversity.nl

Ko de Ruyter

Ko.De-Ruyter.1@ city.ac.uk

Mathew Chylinski

m.chylinski@unsw.edu.au

Dominik Mahr

d.mahr@maastrichtuniversity.nl

Debbie I. Keeling

D.I.Keeling@lboro.ac.uk

1 Department of Marketing and Supply Chain Management, Maastricht University, Tongersestraat 53, 6211

LM Maastricht, The Netherlands

2 Cass Business School, City University London, 106 Bunhill Row, London EC1Y 8TZ, UK

3 UNSW Business School, University of New South Wales, Sydney, NSW 2052, Australia

4 Service Science Factory, Maastricht University, Tongersestraat 6, 6211 LM Maastricht, The Netherlands

5 School of Business and Economics, Loughborough University, Ashby Road, Loughborough LE11 3TU, UK presence on utilitarian value perceptions is greater for customers who are disposed toward verbal rather than visual information processing, and the positive effect on decision comfort is attenuated by customers' privacy concerns.

Keywords Augmented reality - Online service experience . Service marketing strategy $\cdot$ Situated cognition $\cdot$ Spatial presence

\section{Introduction}

With the steadily increasing prevalence of online business, firms face formidable challenges with regard to providing compelling customer experiences at the online organizational frontline. Customer satisfaction with - and trust in - privacy safeguards remains low, as do conversion rates (McDowell et al. 2016). Virtual shopping cart abandonment and product return rates continue to rise, partly because of the limited service scope of online retailers (Janakiraman et al. 2016). As online shopping is considered to be a service experience (e.g., Dabholkar and Bagozzi 2002), developing an innovative, distinctive service strategy to tackle these challenges is crucial for driving firm value (Dotzel et al. 2013). Such a strategy must acknowledge that many online customers find it hard to visualize how products fit into their personal environments or get a feel for a service experience (Cadirci and Kose 2016). To enhance customer affinity for online offerings and facilitate online decision making, many firms (e.g., IKEA, L'Oreal, De Beers, Westpac, UPS, American Apparel, Volvo, Marriott) have adopted a strategy of service augmentation, focusing not on the core product but on the interaction between customers and the organizational frontline (Grönroos 1990). To simulate aspects of service that normally are reserved for in-store shopping experiences, they leverage augmented reality (AR) applications (Brynjolfsson et al. 2013) that contextualize products 
by embedding virtual content into the customer's physical environment, interactively and in real-time (Azuma et al. 2001).

According to Apple CEO Tim Cook, AR-based experiences allow for "a more productive conversation" (CNBC 2016). Apple refers to AR as a core technology and actively pursues an AR-related acquisition strategy. With AR, customers can dynamically engage with goods and services, for example by virtually placing an IKEA sofa in a real-time view of their living room, changing the Dulux color of their wallpaper, or trying on the latest style of sunglasses, clothing, or makeup in a virtual mirror. Thus AR helps customers see how products fit them personally or in their environments, while still maintaining the convenience of online purchasing. From a service augmentation perspective, AR is a "smart" technology (Marinova et al. 2017), set to enhance online service experiences through a more intuitive, context-sensitive interface that aligns with the ways customers naturally process information. Such an advanced frontline interface can improve service quality and offer customers more effective, enjoyable online shopping (Huang and Liao 2015).

A recent industry report forecasts that investments in ARenabled service augmentation will exceed $\$ 2.5$ billion in 2018 (ABI Research 2013). However, due to inflated expectations there are concerns about the business reality of these market projections (Gartner 2015). Customers expect AR to deliver experiential benefits while also reducing their decisionmaking uncertainty (Dacko 2016), but most extant research into AR is limited to a focus on generic technology acceptance models (e.g., Rese et al. 2016). Furthermore, compound annual growth rates for AR are estimated primarily using device types and industry segmentation, rather than specific online customer needs (e.g., visualization of offerings) and concerns (e.g., privacy). Therefore, these projections may not be a bellwether for sustained success; firms face a clear risk of building AR solutions that customers will not embrace. Service managers need a more in-depth understanding of which customers are likely to engage with this new technology, what makes for a compelling experience, and how AR can improve decision making. The paucity of knowledge on these matters also reveals the strong managerial need to understand how the deployment of AR can transform online shopping into a valueadded service experience. By addressing three critical issues, this article contributes to emerging research on the methods available to enhance online service experiences.

First, we draw on situated cognition theorizing (Robbins and Aydede 2009) to show that customers' information processing is embedded in their physical environment and embodied through physical simulations and actions. That is, situated cognition enables customers to learn more about the value of an offering when the associated service experience enables them to link abstract "facts" with a real-time context and physical interaction (e.g., trying on or trying out a product). We conceptualize AR-based service augmentation as a strategy to enhance the customer's ability to interact with online offerings in two interrelated ways: (1) environmentally embedding the offering in a personally relevant context (e.g., projecting a visualization of sunglasses on the customer's face or furniture items into their home) and (2) simulating physical control over the offering (e.g., being able to perform natural movements to adjust the sunglasses or furniture). The lack of these capabilities to personally experience an offering traditionally has made it difficult for customers to engage in effective, enjoyable online shopping (Childers et al. 2001). In line with contemporary services theorizing (e.g., Dabholkar and Bagozzi 2002), we view online shopping as a technology-based service experience and assess whether the AR-enabled interaction effect of simulated physical control and environmental embedding positively influences customers' utilitarian and hedonic value perceptions of the online service experience.

Second, we examine the influence of this interaction by conceptualizing and empirically assessing the mediating role of spatial presence. When a customer senses spatial presence, the online service experience becomes "real." He or she neglects the technology-mediated nature of the experience (ISPR 2000; Lombard and Snyder-Duch 2001). The strength of this feeling is jointly determined by the possibilities for action that a technology offers and how well these possibilities are integrated into the person's immediate environment (Carassa et al. 2005; Schubert 2009). The concept of spatial presence thus captures customers' convictions that they are experiencing an authentic, situated experience, in which virtual content is located in their physical reality and available for interaction (Wirth et al. 2007). In other words, the online service experience is enhanced and decision comfort increases when customers forget about the role of AR and believe they are really trying on and interacting with an "actual" pair of sunglasses, a new makeup look, or clothing from next season's fashion line. Spatial presence sheds light on the process through which AR-based service augmentation translates into favorable customer evaluations of the online service experience, in terms of both perceived value and decision comfort.

Third, we propose two important customer-related boundary conditions for deploying $\mathrm{AR}$ as a service augmentation strategy: (1) style of information processing and (2) privacy concerns. Previous research shows that the effectiveness of visual product representations depends on individual preferences for visual versus verbal processing (Wyer et al. 2008). Jiang et al. (2007) demonstrate for example that adding a visual representation to a verbal description of an offering has little impact on the offering's evaluation for visualizers, because they rely predominantly on their own mental imagery. We anticipate that the spatial presence offered by AR may have a stronger impact on the value perceptions of those who are inclined to rely on semantic processing (i.e., verbalizers), such that AR-enabled visualizations might complement 
their verbal processing style. Because AR technologies also record personal data (e.g., facial recognition), customer concerns about privacy are another pertinent issue (Dacko 2016). Perceptions of risk and vulnerability are associated with data privacy (Martin et al. 2017) and could interfere with the comforting effect of spatial presence for customer decision making. Noting the significant differences in the degree to which customers expect transparency and disclosure of how their data is collected and used, we assess whether customers' concerns about their awareness of a firm's privacy practices attenuate the impact of spatial presence on decision comfort.

\section{Conceptual framework}

Various academic disciplines address AR, including information systems (e.g., Milgram and Kishino 1994), education (Dunleavy et al. 2009), and psychology (Riva et al. 2016). Within the marketing domain, substantial research has focused on customer acceptance modeling, though a growing research stream also recognizes the potential of AR to enhance customer service experiences in a multichannel environment. In Table 1 we summarize selected relevant literature, revealing common research themes and gaps. In particular, recent research emphasizes that AR is able to deliver a compelling user experience (e.g., Poushneh and Vasquez-Parraga 2017), and AR is also expected to benefit customer decision making (Dacko 2016). Many studies share an appreciation for AR's ability to embed virtual content into reality and enable interactions with the content. However, despite initial research efforts (Javornik 2016b), a substantive conceptualization and empirical investigation of these AR features is lacking. Furthermore, there is limited insight into AR-specific process variables or relevant boundary conditions.

Addressing these research gaps is important to differentiate the AR value creation process from that of other interactive technologies. We draw on emerging theories of situated cognition to explain how AR-based service augmentation aligns customer online interactions with natural information processing to influence decision making. A situated cognition perspective implies that information processing occurs within (i.e., is embedded in) and actively exploits (i.e., embodies) a person's environment, rather than taking place as an abstract activity in the mind (Robbins and Aydede 2009; Semin and Smith 2013).

First, with regard to embedding, research has shown that customers not only mentally picture themselves trying out an offering (e.g., Escalas 2004) but also use their immediate environment to facilitate such visualization. For example, customers often lay out the parts of self-assembly furniture in the correct spatial proportions (Wilson 2002). As such, we propose that AR facilitates situated information processing by providing customers with a service to embed a product in a personally relevant context (e.g., fitting a virtual image of sunglasses or makeup on the customer's face, projecting a sofa into their living room). We conceptualize this aspect of AR as environmental embedding, defined as the visual integration of virtual content into a person's real-world environment. Services researchers have emphasized that enabling customers to mentally grasp the qualities and benefits of an offering (e.g., through enhanced visualization) reduces perceived risk (Laroche et al. 2004). Mentally picturing how furniture from an online shop fits with the existing decor or how sunglasses look when worn may be too complex for customers. Environmental embedding relieves customers of this mental burden and provides enhanced information about how an offering relates to the context in which customers use it.

Second, embodiment implies that customers' information processing is tightly coupled with their experience of bodily simulations, states, and actions (Barsalou 2008; Niedenthal 2007). Accordingly, the importance of perceived control in service experiences is well acknowledged (Zhu et al. 2007); research has shown that particularly physical interaction with an offering evokes affective reactions in form of pleasure and improves the customer's ability to evaluate the offering (Grohmann et al. 2007). We thus propose that AR enables an embodied online service experience by allowing customers to control a virtual product using the same physical movements they would use for an actual product (Rosa and Malter 2003). We conceptualize this ability of AR to simulate physical control over an offering (e.g., moving, rotating) as embodiment, labeled simulated physical control.

In sum, we discern the simultaneous provision (1.e., conjunction) of environmental embedding and simulated physical control as the unique property of AR-based service augmentation. AR thus provides highly situated experiences that likely outperform current online service experiences with 360-degree product rotations or photo-based try-on, as these only partially fulfill customers' needs for embodiment and embedding.

Following Grönroos (1990), in our conceptualization, ARbased service augmentation seeks to enhance not only the product offering but also the interaction between customers and the online organizational frontline. For customers, this means that AR may provide a context-sensitive interface with enriched information (Yaoyuneyong et al. 2016) and a different form of interaction compared with current technologies (Javornik 2016b). Traditional (in-store) shopping allows for personal examination of offerings (Childers et al. 2001), and AR-based service augmentation brings this service aspect to the online environment. Specifically, customers can virtually view a product at home, use it in another environment, or even try it on virtually (Kim and Forsythe 2008). Such "smart" frontline interactions allow customers to engage in more productive inquiry and action, resulting in enhanced service experiences and decision making (Marinova et al. 2017).

As part of an innovative service strategy, AR-based service augmentation offers firms the means to achieve favorable customer behavioral outcomes (e.g., purchase behavior, word-of-mouth) and enhance their bottom lines (Dacko 2016). It is a readily 


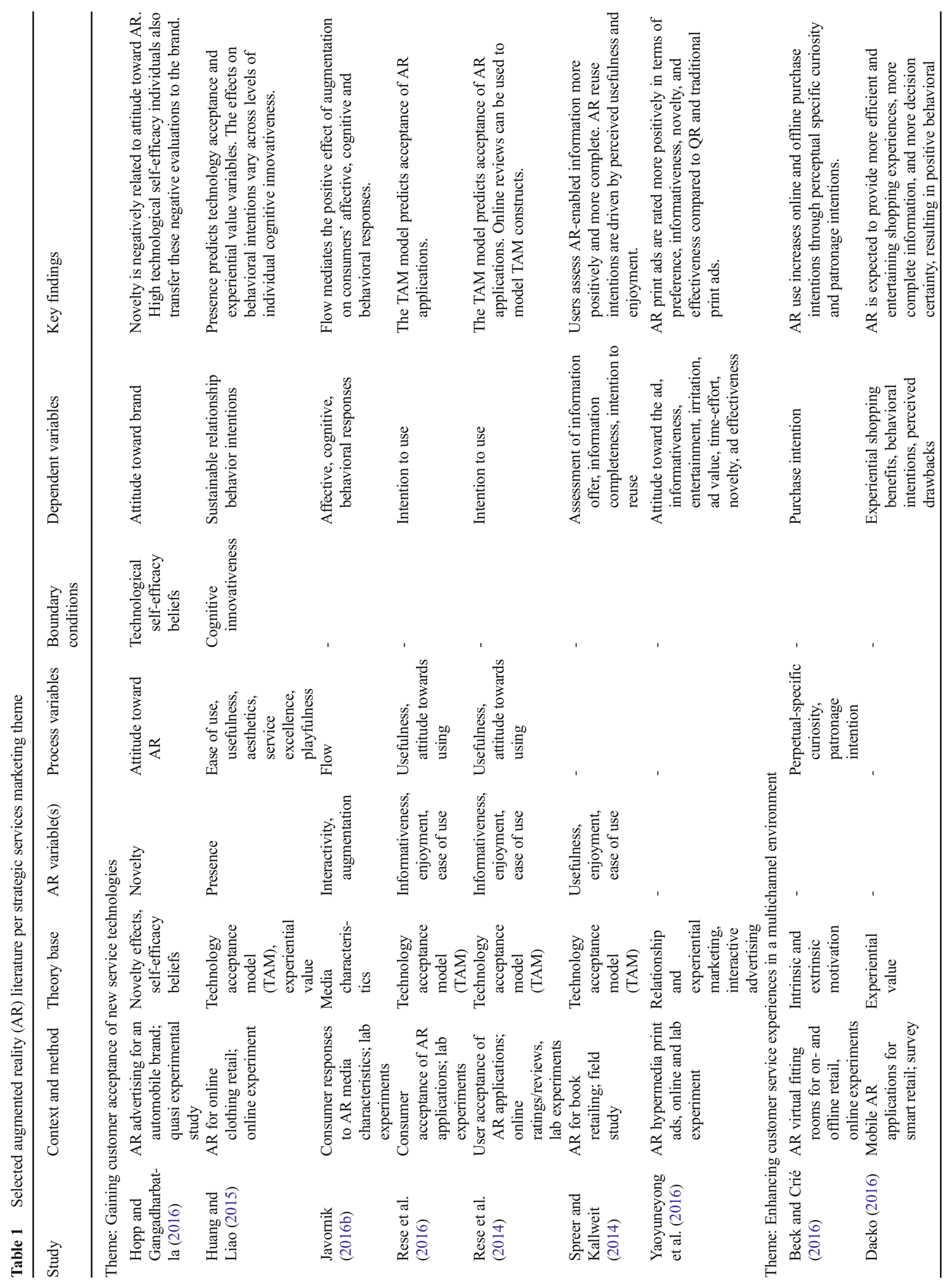




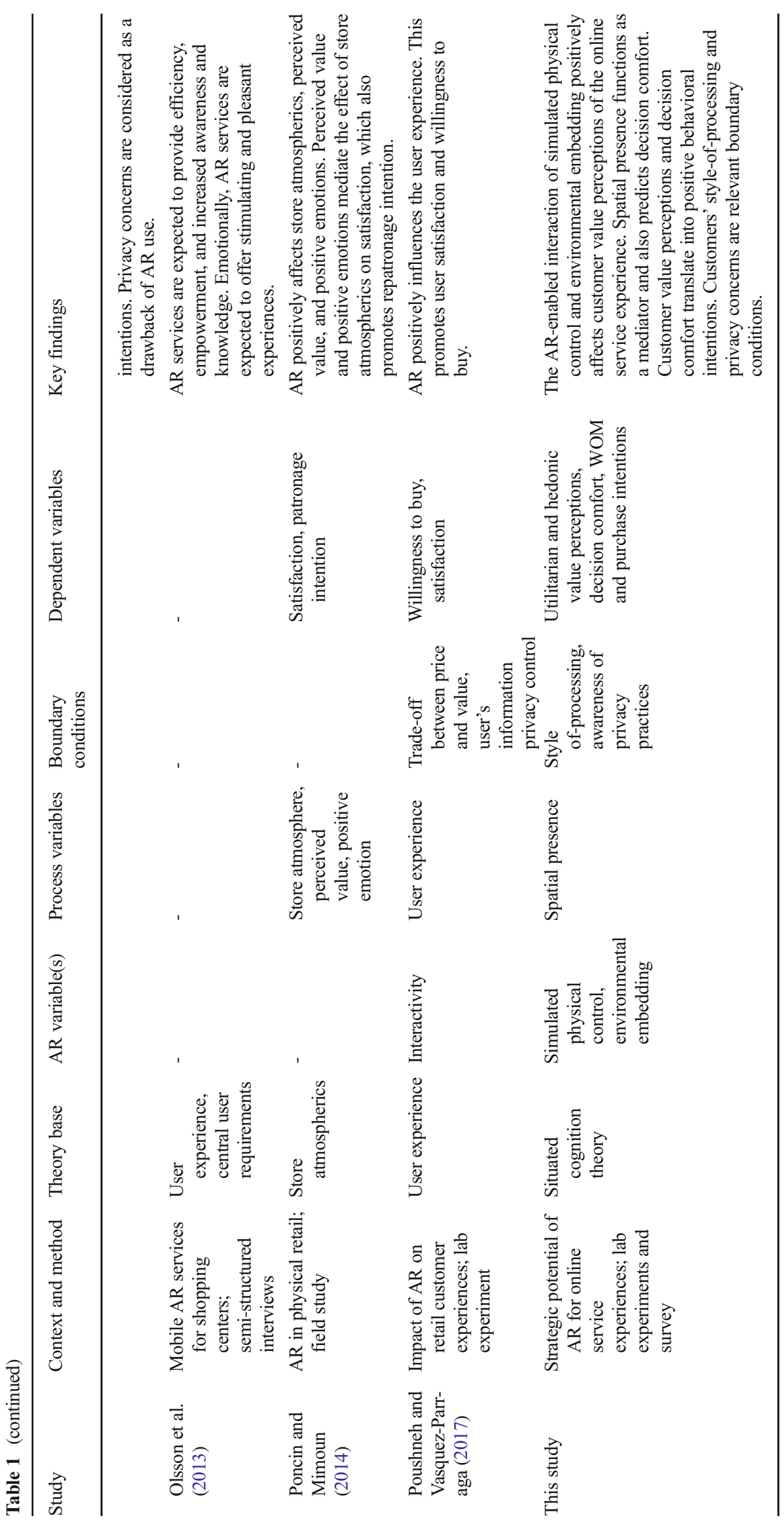


adoptable technology that works on existing (customer-owned) devices (McKone et al. 2016), and AR-enhanced online service experiences may help deliver on services marketing imperatives (Berry 2016): competing on value, meeting or exceeding customer expectations, saving customers time and effort (including enhancing decision making ability), and being generous. For customers, AR's enrichment and enhancement of online interactions offers a close alignment with their natural information processing, so it can provide a sense of comfort in online decision making. For example, customers perceive AR-enhanced advertisements as more informative and effective than their print counterparts (Yaoyuneyong et al. 2016). The potential of AR-based service augmentation to offer hedonic value, such as entertainment and shopping enjoyment, also should lead to higher customer satisfaction (Childers et al. 2001). Finally, AR-based service augmentation addresses customers" "pain points" (e.g., travel, time constraints) while still offering personalized experiences (e.g., virtual applications that learn and apply customers' preferences; McKone et al. 2016). Because AR-based service augmentation may lead to more enjoyable, effective online shopping and more comfortable decision making, it should increase perceived service quality and conversion rates, while reducing the likelihood of product returns. Considering the strategic potential of AR-based service augmentation, we develop testable hypotheses of its impact on marketing-relevant outcome variables.

\section{Hypotheses development}

What is unique about the situated cognition perspective on ARbased service augmentation is the interdependence of environmental embedding and simulated physical control. Effective environmental embedding depends on embodied actions to alter the immediate environment in a strategic manner (Robbins and Aydede 2009). The value of environmentally embedding a pair of sunglasses on a customer's face depends on the ability to perform and register physical movements in such a way that the customer can view the glasses from different angles and develop a feel for the offering. Images of models wearing the sunglasses or a photo-based try-on cannot provide such an embodied online service experience. In turn, possibilities for embodied action arise from a dynamic relation between a person and his or her environment (Clancey 2009; Gibson 1979). Therefore, embodied action becomes meaningful for customers only if it is embedded in their immediate physical environment. Without such embedding in the relevant context, simulated physical control is less effective (i.e., online service experiences with 360-degree product rotation only partially fulfill customers' cognitive needs). In contrast, AR provides a service experience that enables customers to exert physical control over offerings in their immediate environment, resulting in a more natural way of processing information about the offering.

It is broadly acknowledged that customers evaluate service experiences in terms of both utilitarian and hedonic value
(Bauer et al. 2006; Babin et al. 2005), where the former captures the performance-related effectiveness and the latter the experiential enjoyment provided in a service experience. For example, Childers et al. (2001) demonstrate that customers assess both the usefulness and enjoyment of an online grocery shopping service. Recent studies suggest that the use of AR in a retail context enhances customer perceptions of both these value dimensions in the holistic shopping experience (e.g., Poncin and Mimoun 2014). The ability of AR to let customers virtually try on (i.e., environmentally embed) online offerings provides enhanced information (Poushneh and Vasquez-Parraga 2017) and a visually appealing experience (Huang and Liao 2015); it relieves customers of the mental burden of imagining how, for example, a pair of sunglasses would look when worn. The accompanying form of (simulated physical) control offered by AR differs from traditional web-based user control (Javornik 2016b); it allows customers to physically evaluate and playfully interact with a virtual offering, even though the offering is not physically present (Rosa and Malter 2003). In sum, AR should promote an effective, enjoyable online service experience because the interaction of environmental embedding and simulated physical control aligns with customers' naturally embedded and embodied way of processing information. Whilst there may be individual effects of enabling an embodied or embedded online service experience, our theory-based prediction is that it is through their joint effect that AR makes online service experiences more effective and enjoyable for the customer. We therefore postulate:

H1: Simulated physical control and environmental embedding have a positive interaction effect on customers' utilitarian and hedonic value perceptions of the online service experience.

The AR-enabled interaction of simulated physical control and environmental embedding provides customers with the means to engage in a situated online service experience. The authenticity of this service experience - that is, how well AR simulates trying on a pair of sunglasses in a physical store-is reflected in customers' feelings of spatial presence. Spatial presence describes a distinct psychological state in which a person neglects the role of technology in an experience (ISPR 2000; Lombard and Snyder-Duch 2001); he or she consequently feels physically situated in a different location and perceives possibilities for action (Wirth et al. 2007). Spatial presence is conceptually distinct from constructs such as involvement (Schubert et al. 2001; Wirth et al. 2007) and transportation (Lombard and Snyder-Duch 2001). A feeling of presence can be achieved in augmented environments; its lev$\mathrm{el}$ is contingent on the person's control over at least one sense and the ability to alter the environment (Riva et al. 2016). Accordingly, the situated view of presence holds that for a person the sense of "being there" requires the ability for them 
to "do there" (Schultze 2010; see also Sanchez-Vives and Slater 2005), and AR-based service augmentation offers this ability. The interaction of simulated physical control and environmental embedding provides opportunities for action and the meaningful integration of these actions into the environment, which in turn elicits a strong sensation of spatial presence for a person (Schubert 2009; Schultze 2010).

However, an AR setting demands modification to our understanding of spatial presence (Schubert 2009). Rather than feeling present in wholly artificial environments (e.g., virtual shopping mall), customers should sense that virtual products are present and can be interacted with in their real world. In that respect, AR spatial presence is consistent with conceptualizations of object presence (Stevens et al. 2002) or "it is here" presence (Lombard and Ditton 1997). Using spatial presence as the metric of success for AR-based service augmentation thus requires replacing a person's feeling of "self-location" with a feeling of "object-location" in the physical reality. Spatial presence is a consciously experienced cognitive feeling that varies in intensity and has informative value and positive valence; the opposite state (not feeling present) is manifested as a negative state of disorientation (Schubert 2009). As such, spatial presence intensifies media effects (Wirth et al. 2007) and can explain the effect of AR-based service augmentation on customer value perceptions of the online service experience. Customers become convinced of the authenticity of the situated service experience and feel that they are actually trying on, for example, a pair of sunglasses as in a physical service encounter. In support of this hypothesizing, Klein (2003) demonstrates positive effects of a sense of presence on the strength of customers' beliefs about product attributes and attitudes toward products. Moreover, Fiore et al. (2005) find a significant effect on customer perceptions of instrumental and experiential value. Therefore:

H2: The positive interaction effect of simulated physical control and environmental embedding on customers' utilitarian and hedonic value perceptions of the online service experience is mediated by spatial presence.

Although the success of AR-based service augmentation likely relates to the aspects that align with a customer's natural, situated information processing and the resulting feeling of spatial presence, it is unlikely that all customers realize these benefits equally. Previous research investigates the influence of divergent personal traits, such as trait absorption, emotional involvement (Wirth et al. 2012), and mental imagery ability (Weibel et al. 2011), on the emergence of spatial presence. But a paucity of knowledge describes individual differences in the value derived from spatial presence. Insight into which customers find ARbased service augmentation valuable is important for service managers. Because the predominant modality of AR is visual, customers' responses to AR-based service augmentation are likely influenced by idiosyncrasies in how they process visual information. After all, most AR platforms overlay virtual content in a customer's visual field through a computer screen, such as seeing a virtual pair of sunglasses on one's own face.

Irrespective of domain-specific processing abilities, Childers et al. (1985) show that customers differ in their preference for a visual versus verbal style-of-processing. Visualizers prefer to process information through the construction of visual images, whereas verbalizers prefer semantic processing without forming images. Drawing on evidence that object evaluations are negatively influenced by the associated processing difficulty (Winkielman et al. 2003), Wyer et al. (2008) contend that the effectiveness of product visualization depends on a customer's dispositional style-of-processing. Adding pictures to verbal descriptions of familiar products thus has less effect on product evaluations for visualizers than for verbalizers (Jiang et al. 2007), because they already mentally form visual images of described products, so the pictures convey little additional information. In contrast, verbalizers derive additional information from pictures. Thus, in online service experiences, customers who are verbalizers likely use the enhanced visualization experienced during spatial presence (i.e., feeling that products are situated in reality and available for interaction). Accordingly, we posit that verbalizers derive more utilitarian value from improved possibilities for engaging in better product evaluation - and thus experience more effective online shopping - but they also experience greater hedonic value due to reduced processing difficulty. Formally:

H3: The positive relationship between spatial presence and customers' utilitarian and hedonic value perceptions of the online service experience is stronger for verbalizers than for visualizers.

Extant research has shown that customers expect not only experiential benefits from AR use for online shopping but also reduced decision uncertainty (Dacko 2016). In support of this view, many service delivery models emphasize the importance of achieving consumer comfort in service interactions (Spake et al. 2003). The concept of decision comfort, defined as the degree to which customers feel at ease or contented with a specific decision, has been introduced as an important element of a customer's decision experience (Parker et al. 2016). Decision comfort constitutes a soft-positive affective response that can account for variations in customers' overall evaluations of a decision experience, beyond generic affect and decision confidence. The latter reflects the level of certainty about making the best choice (based on a cognitive assessment of the pros and cons of a decision), but decision comfort is an affect-based sense of ease related to the process of making the choice. Parker et al. (2016) thus argue that a customer's decision comfort is driven by affect-laden cues. ARbased service augmentation is deployed to enhance the customer decision process through spatial presence, which is an affectbased cue. Spatial presence thus should be conducive to an 
experience that promotes ecological validity for the customer, marked by positive affect. Schubert (2009) argues that as a result, customers' perceptions of assurance grow, because customers regard the attributes of virtual objects as if they were real. This sense of a first-hand experience with online offerings, approximating a real-world service experience, allows customers to feel at ease with a decision. Therefore:

H4: There is a positive relationship between spatial presence and decision comfort.

Customer concerns about marketers collecting and using personal information continue to be a pertinent issue (Martin et al. 2017), particularly in relation to AR technologies (Dacko 2016). The failure of Google Glass (an early entrant into the AR market) may have been due to concerns about its privacy implications (Downes 2013). Because AR technologies record personal data by employing facial recognition or spatial tracking functionalities, perceptions of risk and vulnerability are considerable and could have negative ramifications for the application of AR in online service experiences. Customers' general information privacy concerns relate to their subjective perception of the fairness of the way their personal information is treated; though opinions about what is fair differ among customers. We contend that a specific dimension of privacy concerns related to customers' concerns about their awareness of privacy practices used by firms is pertinent to the use of AR. These concerns about awareness are based on a sense of interactional and informational justice, related to transparency and disclosure of how a firm collects and uses personal information (Malhotra et al. 2004). Since AR technology makes use of novel information collection methods, customers are likely to be concerned about transparency (Downes 2013) and being adequately informed about the associated privacy practices - that is, how their images in a virtual mirror or pictures of their homes are collected, processed, and used.

Previous research, however, has shown that considerable differences exist in the extent to which customers are concerned about their awareness of privacy practices. On the one hand, many customers do not make the effort to read privacy policies or find privacy statements too difficult to understand fully (Tsai et al. 2011). On the other hand, for some customers it is important to be highly cognizant of firm privacy practices. Although we expect an inverse relationship between customers' concerns about their awareness of privacy practices and decision comfort, our focus is on testing these privacy concerns as a boundary condition for the impact of spatial presence on decision comfort. We posit that the more customers are concerned with being fully aware of the privacy practices associated with using, for example, an AR virtual mirror, the more likely these concerns are to interfere with their immersion in the mediated experience (Draper et al. 1998). Associated perceptions of risk and vulnerability may cast doubt on the nature of the authentic, situated experience offered by AR and attenuate the comforting effects of spatial presence for customer decision making. Therefore:

H5: The positive relationship between spatial presence and decision comfort is attenuated by customers' concerns about their awareness of a firm's privacy practices.

\section{Research model and empirical studies}

We conducted a series of studies to test our hypotheses empirically (see Fig. 1 for an overview). Studies 1, 2, and 3 explore

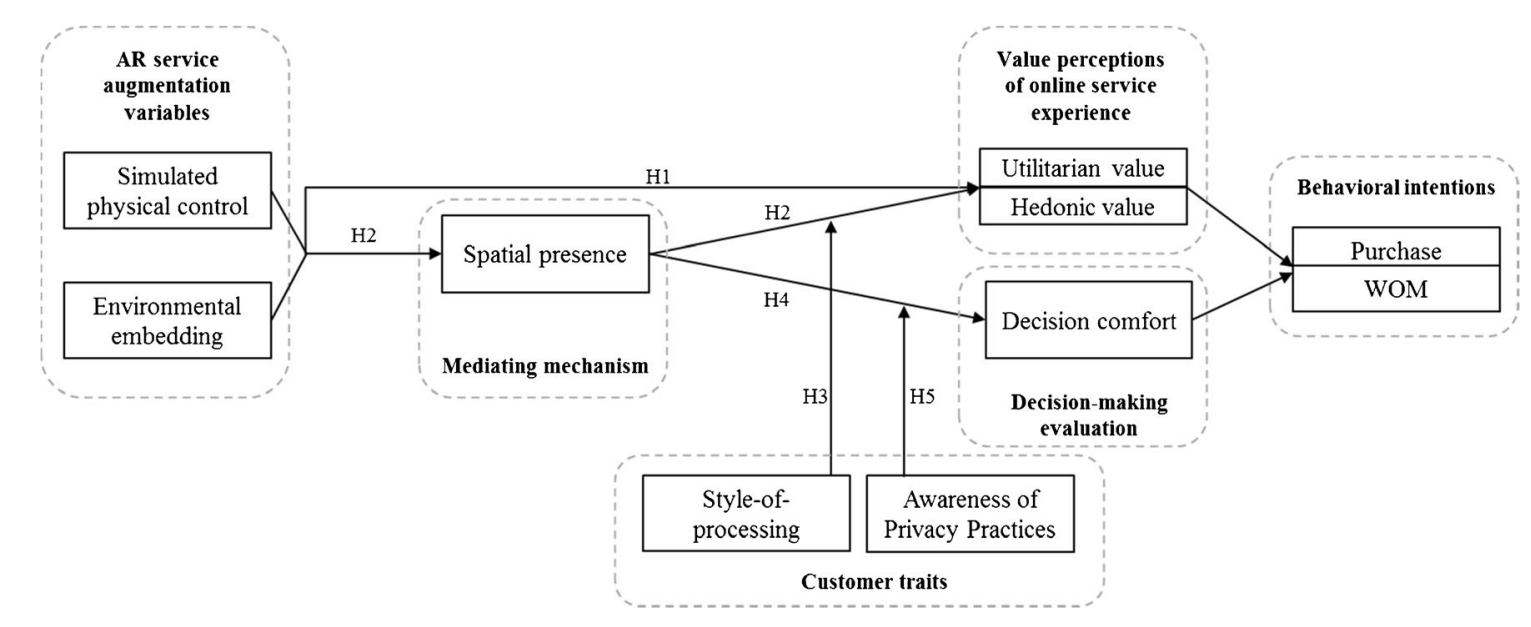

Fig. 1 Overall research framework with all hypotheses 
the potential of AR to enhance the online service experience in terms of utilitarian and hedonic value. Specifically, in Study 1, participants tried out the AR virtual mirror of the largest European online eyewear retailer (Mister Spex; https://www. misterspex.co.uk) and evaluated the experience (H1). In Study 2, we used L'Oreal's AR virtual mirror for makeup (Makeup Genius; http://www.loreal-paris.co.uk/make-up/makeupgenius) to investigate the mediating role of spatial presence (H2). In Study 3, we examined customers' processing style as a boundary condition (H3); we also analyzed whether the benefits of AR-based service augmentation translated into positive behavioral intentions. Then in Study 4, we extend our analysis to investigate the role of AR for customer decision making. We varied the study design so that participants made a purchase decision and subsequently rated their associated decision comfort (H4) and behavioral intentions. We also investigated their privacy concerns as a boundary condition (H5).

\section{Study 1}

\section{Design and procedure}

In Study 1, we tested the prediction in $\mathrm{H} 1$ that simulated physical control and environmental embedding $(\mathrm{SPC} \times \mathrm{EE})$ have a positive interaction effect on customers' utilitarian and hedonic value perceptions of the online service experience. To ensure that we tested an appropriate target group, we recruited 176 participants between 17 and 31 years of age from a large public university. According to recent market surveys (Nielsen 2014, 2015), this generation of digital natives is adept at and keen to use technology for online shopping. All participants received course credit for attending a lab session in which they sat at desktop computers equipped with frontfacing webcams. We presented participants an image of the Mister Spex online shop and tasked them with trying out and evaluating an application that was to be added to the website. Depending on the assigned condition, each participant then tried one version of the AR virtual mirror and completed a survey. Across all studies, we applied the same set of prespecified quality criteria and excluded participants from further analysis if they experienced technical difficulties (13), indicated that they did not understand the instructions (3), or provided incomplete responses (2). We also identified and removed two univariate outliers $(1.1 \%)$. This resulted in a final sample of 156 participants ( 79 women, 77 men) in a 2 (low versus high $\mathrm{SPC}) \times 2$ (low versus high $\mathrm{EE}$ ) betweensubjects design.

To create the desired experimental manipulations, we replicated the Mister Spex AR virtual mirror and altered the extent to which it provided simulated physical control and environmental embedding across conditions (see also Appendix
Table 2 Study 1: Regression results

\begin{tabular}{lll}
\hline Independent variables & $\begin{array}{l}\text { Utilitarian } \\
\text { value }\end{array}$ & $\begin{array}{l}\text { Hedonic } \\
\text { value }\end{array}$ \\
\hline Constant & $3.64^{* *}$ & $3.43^{* *}$ \\
Simulated physical control & $(.13)$ & $(.11)$ \\
& .09 & -.04 \\
Environmental embedding & $(.18)$ & $(.15)$ \\
& -.11 & .13 \\
Simulated physical control $\times$ environmental & $(.17)$ & $(.15)$ \\
$\mathrm{R}^{2}$ embedding & $.50^{*}$ & $.63^{* *}$ \\
MSE & $.24)$ & $(.21)$ \\
$\mathrm{F}$ & .08 & .18 \\
$\mathrm{df}$ & .57 & .42 \\
& $4.45^{* *}$ & $11.19^{* *}$ \\
\hline
\end{tabular}

The numbers in parentheses are standard errors. Unstandardized coefficients are shown. Significance based on two-tailed test.

$* * p<.01 . * p<.05$

B). To avoid confounding effects, we designed the application for each condition so that it accurately resembled an existing online service. ${ }^{1}$ Participants provided with the full AR virtual mirror application could see the sunglasses fitted to their face in real time (high environmental embedding) and could move the sunglasses through head movements (high simulated physical control). Participants in the high EE-low SPC condition received an application resembling a photo-based tryon, in which they could see the sunglasses on their face but did not have physical control over them. For the high SPC-low EE condition, we created a 360-degree product rotation, which allowed participants to control the sunglasses physically (with hand movements, consistent with the physical control participants have when examining a real pair of sunglasses, without a means to try them on) on a decontextualized white background. Participants in the control group (low EE-low SPC) viewed a static image of the sunglasses on the white background of the online retailer's website.

\section{Measures}

To measure customers' utilitarian and hedonic value perceptions of the online service experience, we adapted two constructs by Childers et al. (2001). Specifically, we employed a three-item measure $(\alpha=.85)$ that asked participants to rate the effectiveness of the technology-assisted shopping experience with the provided application. We assessed hedonic value perceptions (i.e., customers' enjoyment of the technology-assisted

\footnotetext{
${ }^{1}$ To ensure that our manipulations of simulated physical control and environmental embedding did not create confounds of perceived technological functionality, we conducted an additional study $(n=195)$, in which we allowed participants to try the AR virtual mirror for eyewear with the same manipulations as in Study 1. We asked them to rate its functionality, on an adapted 5item measure (Lin and Hsieh $2011 ; \alpha=.67$ ). The regression analysis revealed that the functionality measure did not respond to $\operatorname{SPC}(\beta=.10, p=.43)$, EE ( $\beta=-.22, p=.08)$, or their interaction $(\beta=.17, p=.31)$, thus ruling out potential confounding effects.
} 
Fig. 2 Study 1: Effects of simulated physical control with high or low environmental embedding on utilitarian and hedonic value perceptions of the online service experience

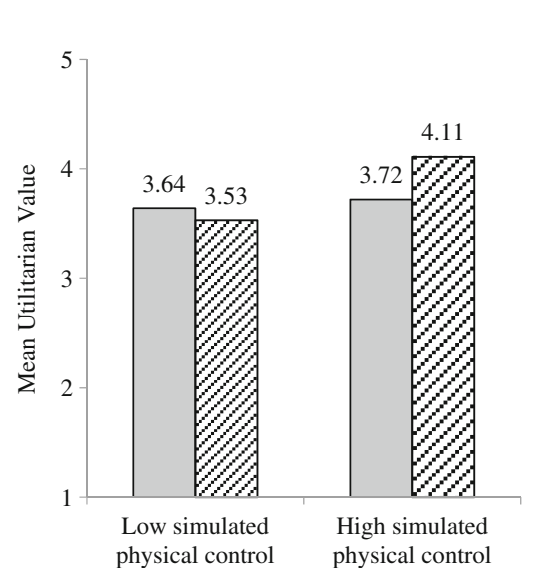

shopping experience) with a four-item measure $(\alpha=.90)$. Participants responded to all measures on five-point Likert scales ("strongly disagree" $=1$ to "strongly agree" $=5$ ). We provide the items for all constructs in Appendix A.

\section{Results}

Manipulation checks To assess the success of our manipulations, we asked participants to rate two single-item measures (SPC: "I was able to move the sunglasses around"; EE: "I was able to see how the sunglasses look on my face") on a fivepoint Likert scale ("strongly disagree" = 1 to "strongly agree" =5). As intended, participants in the high SPC condition perceived significantly greater simulated physical control than those in the low SPC condition $\left(\mathrm{M}_{\mathrm{HighSPC}}=4.37\right.$, $\left.\mathrm{M}_{\text {LowSPC }}=2.71, \mathrm{t}(134)=-10.48, p<.001\right)$. The measure for environmental embedding also yielded significant differences in the anticipated direction between the high and low EE conditions $\left(\mathrm{M}_{\mathrm{HighEE}}=3.95, \mathrm{M}_{\text {LowEE }}=2.21, \mathrm{t}(154)=-10.83\right.$, $p<.001)$.

Moderation analysis To investigate $\mathrm{H} 1$, we used the PROCESS macro (Hayes 2013, Model 1) with a simple effects parameterization and individually regressed utilitarian and hedonic value on SPC, EE, and their interaction (low SPC $(E E)=0$, high SPC $(E E)=1) .{ }^{2}$ We found support for $\mathrm{H} 1$, with a significant $\mathrm{SPC} \times \mathrm{EE}$ interaction effect on utilitarian $(\beta=.50$, $p=.041)$ and hedonic $(\beta=.63, p=.003)$ value. No significant effects of SPC or EE emerged (Table 2), revealing that in the low SPC (EE) condition, there were no significant differences

\footnotetext{
2 Throughout our studies we used PROCESS because it let us analyze the hypothesized conditional effects $(\mathrm{H} 1, \mathrm{H} 5)$ and conditional indirect effects (H2, H3) with a consistent method of analysis and allowed for bootstrapbased inference. PROCESS produces equivalent results to an ANOVA for our focal interaction; however, it does not allow for multivariate analysis. We therefore conducted MANOVAs with utilitarian and hedonic value perceptions as a combined dependent variable in Studies 1, 2, and 3; the multivariate test results are consistent with the results obtained from our analysis with PROCESS.
}

in utilitarian or hedonic value between the high and low EE (SPC) conditions (Fig. 2). However, in the high SPC condition, participants with high (versus low) EE reported significantly higher utilitarian $\left(\mathrm{M}_{\mathrm{HighEE}}=4.11, \mathrm{M}_{\mathrm{LowEE}}=3.72\right.$, $\mathrm{t}(152)=2.29, p=.023)$ and hedonic $\left(\mathrm{M}_{\mathrm{HighEE}}=4.14\right.$, $\left.\mathrm{M}_{\text {LowEE }}=3.38, \mathrm{t}(152)=5.19, p<.001\right)$ value. Similarly, in the high EE condition, participants with high (versus low) SPC reported significantly higher utilitarian $\left(\mathrm{M}_{\mathrm{HighSPC}}=4.11\right.$, $\left.\mathrm{M}_{\text {LowSPC }}=3.53, \mathrm{t}(152)=3.49, p<.001\right)$ and hedonic $\left(\mathrm{M}_{\text {HighSPC }}=4.14, \mathrm{M}_{\text {LowSPC }}=3.55, \mathrm{t}(152)=4.09, p<.001\right)$ value.

\section{Discussion}

The results of Study 1 provide evidence of the benefits of ARbased service augmentation. Specifically, and consistent with our prediction, customers' value perceptions of the online service experience - underpinned by situated cognition - are highest under the AR-enabled condition of high simulated physical control and high environmental embedding. Although this combination aligns with customers' natural information processing, we further theorize that customers must be convinced that AR provides an authentic situated experience, in which the virtual content leveraged by AR is actually embedded in the physical reality and allows for embodied action (H2). We therefore turn to an investigation of spatial presence as an underlying process variable in Study 2.

\section{Study 2}

To investigate $\mathrm{H} 2$, we conducted a study with an application similar to the previously employed AR virtual mirror, though we varied the product stimuli (makeup instead of sunglasses). We also sought to rule out an alternative mediation account. Previous research has identified psychological ownership as a focal driver of customer product valuations (e.g., Peck and 
Shu 2009) that can be elicited through the ability to control an object physically (Pierce et al. 2003) or vividly imagine ownership (Peck and Shu 2009).

\section{Design and procedure}

We used L'Oreal's AR virtual mirror for makeup in the same 2 (low versus high SPC) $\times 2$ (low versus high EE) between-subjects design as in Study 1. We gathered our sample from AR's main target group and recruited 197 female participants between 18 and 25 years of age from an undergraduate business course. Extra credit served as an incentive for participation. The experimental procedure was equivalent to that in Study 1, though participants used a tablet PC to try one version of L'Oreal's AR virtual mirror for a lipstick product. To create the desired manipulations, we replicated the original application and altered the extent to which it provided simulated physical control (SPC) and environmental embedding (EE) across conditions (see also Appendix B). Participants who used the full AR virtual mirror application were able to see the lipstick applied to their face in real time (high EE) and control the presentation with head movements (high SPC). Participants in the high EE-low SPC condition were able to see a static photo of themselves with the lipstick applied. For the high SPC-low EE condition, we used various angle images of a model wearing the lipstick and merged them into a 360-degree product rotation. Participants could physically control the presentation (high SPC) but could not see the lipstick personally applied (low EE). We excluded participants who did not try out the application (12) or experienced technical difficulties (10). We also removed two multivariate outliers (1.0\%), leaving a final sample of 173 participants.

\section{Measures}

In line with previous conceptualizations of spatial presence in an AR context (e.g., Schubert 2009), we adapted the eightitem spatial presence measure by Vorderer et al. (2004) by reversing the logic of the items, from feeling present in another environment to feeling that a virtual object was present in the immediate physical environment. ${ }^{3}$ For example, we adapted the original item, "It was as though my true location

\footnotetext{
3 The spatial presence measure by Vorderer et al. (2004) consists of two subscales. However, the situated perspective on presence (Carassa et al. 2005) and previous research (Weibel et al. 2011) support a unidimensional measure. In Study 2, principal components analysis pointed to a single-factor solution that explains $64.14 \%$ of the variance in the items (KMO measure of sampling adequacy $=.89$; Bartlett's test of sphericity $\chi^{2}(28)=940.55, p<.001$ ). Velicer's minimum average partial test and parallel analysis confirmed a single-factor solution. The same analysis consistently supported unidimensionality in Studies 3 and 4. We therefore collapsed the two subscales into one overall spatial presence measure.
}

had shifted into the environment of the presentation" to "It was as though the true location of the product had shifted into the real world environment." The adapted scale exhibited good internal consistency $(\alpha=.92)$. We included the utilitarian $(\alpha=.90)$ and hedonic $(\alpha=.87)$ value measures from Study 1 , as well as a three-item measure of psychological ownership ( $\alpha=.92$ ) by Peck and Shu (2009). Participants responded to all item batteries on five-point Likert scales ("strongly disagree" $=1$ to "strongly agree" $=5$ ). The items for all measures are in Appendix A.

\section{Results}

Manipulation checks Participants answered two single-item measures (SPC: "I was able to move the lipstick around"; EE: "I was able to see how the lipstick looks on my face") on a five-point Likert scale ("strongly disagree" = 1 to "strongly agree" $=5$ ). These manipulations worked as intended. Participants in the high SPC condition reported significantly greater SPC than those in the low SPC condition $\left(\mathrm{M}_{\mathrm{HighSPC}}=3.69, \mathrm{M}_{\text {LowSPC }}=2.61, \mathrm{t}(164)=-6.63\right.$, $p<.001)$, and participants in the high EE condition indicated significantly greater $\mathrm{EE}$ than those in the low EE condition $\left(\mathrm{M}_{\mathrm{HighEE}}=4.27, \mathrm{M}_{\mathrm{LowEE}}=3.28, \mathrm{t}(140)=-5.80, p<.001\right)$.

Moderated mediation analysis The regression results are in Table 3. The SPC $\times$ EE interaction predicted spatial presence in the mediator model $(\beta=.50, p=.047)$; spatial presence also predicted utilitarian $(\beta=.44, p<.001)$ and hedonic $(\beta=.27$, $p<.001)$ value in the respective dependent variable models. In support of $\mathrm{H} 2$, our bootstrapping procedure with 5000 samples and bias-corrected confidence intervals (CIs) (Hayes 2013, Model 8) yielded a significant indirect effect of SPC through spatial presence on utilitarian value (UV) and hedonic value $(\mathrm{HV})$ in the high $\mathrm{EE}$ condition (UV $\beta=.27,95 \% \mathrm{CI}=.12$ to .46 ; $\mathrm{HV} \beta=.16,95 \% \mathrm{CI}=.06$ to .33 ) but not in the low $\mathrm{EE}$ condition. Furthermore, EE had a positive indirect effect through spatial presence on utilitarian and hedonic value in the high SPC condition (UV $\beta=.29,95 \% \mathrm{CI}=.14$ to .52 ; HV $\beta=.18,95 \% \mathrm{CI}=.07$ to .37 ) but not in the low SPC condition.

Psychological ownership In further support of $\mathrm{H} 2$, we did not find strong evidence for psychological ownership as an alternative mediator. Specifically, the SPC $\times$ EE interaction did not predict psychological ownership in the mediator model. Although psychological ownership had a significant effect on hedonic value $(\beta=.16, p=.007)$, bootstrapping with 5000 samples did not yield significant indirect effects for SPC on hedonic value, in either the low or high EE condition. Furthermore, EE had no significant indirect effect on hedonic value in the low SPC condition; the effect was significant in the high SPC condition though $(\beta=.07,95 \% \mathrm{CI}=.00$ to .19$)$. Thus, there is some evidence that when participants have 
Table 3 Study 2: Regression results

\begin{tabular}{|c|c|c|c|c|}
\hline Independent variables & $\begin{array}{l}\text { Spatial } \\
\text { presence }\end{array}$ & $\begin{array}{l}\text { Psychological } \\
\text { ownership }\end{array}$ & $\begin{array}{l}\text { Utilitarian } \\
\text { value }\end{array}$ & $\begin{array}{l}\text { Hedonic } \\
\text { value }\end{array}$ \\
\hline Constant & $\begin{array}{l}2.92 * * \\
(.14)\end{array}$ & $\begin{array}{l}2.66^{* *} \\
(.18)\end{array}$ & $\begin{array}{l}2.15^{* *} \\
(.24)\end{array}$ & $\begin{array}{l}2.49 * * \\
(.22)\end{array}$ \\
\hline Simulated physical control & $\begin{array}{l}.11 \\
.(18)\end{array}$ & $\begin{array}{l}-.12 \\
(.24)\end{array}$ & $\begin{array}{l}.09 \\
.17)\end{array}$ & $\begin{array}{l}-.16 \\
(.15)\end{array}$ \\
\hline Environmental embedding & $\begin{array}{l}.17 \\
(.18)\end{array}$ & $\begin{array}{l}.05 \\
(.23)\end{array}$ & $\begin{array}{l}.08 \\
(.17)\end{array}$ & $\begin{array}{l}-.02 \\
(.15)\end{array}$ \\
\hline $\begin{array}{l}\text { Simulated physical control } \times \text { environmental } \\
\text { embedding }\end{array}$ & $\begin{array}{l}.50^{*} \\
(.25)\end{array}$ & $\begin{array}{l}.38 \\
(.32)\end{array}$ & $\begin{array}{l}.05 \\
(.23)\end{array}$ & $\begin{array}{l}.29 \\
(.20)\end{array}$ \\
\hline Spatial presence & -- & -- & $\begin{array}{l}.44 * * \\
(.09)\end{array}$ & $\begin{array}{l}.27^{* *} \\
(.08)\end{array}$ \\
\hline Psychological ownership & -- & -- & $\begin{array}{l}.09 \\
(.07)\end{array}$ & $\begin{array}{l}.16^{* *} \\
(.06)\end{array}$ \\
\hline $\mathrm{R}^{2}$ & .13 & .02 & .29 & .27 \\
\hline MSE & .65 & 1.10 & .54 & .43 \\
\hline F & $8.45^{* *}$ & 1.31 & $13.86^{* *}$ & $12.55^{* *}$ \\
\hline $\mathrm{df}$ & 3,169 & 3,169 & 5,167 & 5,167 \\
\hline
\end{tabular}

The numbers in parentheses are standard errors. Unstandardized coefficients are shown. Significance based on two-tailed test

$* * p<.01 . * p<.05$

simulated physical control, adding environmental embedding creates a sense of psychological ownership, which elicits hedonic value. We reflect on this finding in the general discussion.

\section{Discussion}

We provide evidence for $\mathrm{H} 2$ by demonstrating that the ARenabled interaction of SPC and EE provides customers with an authentic situated experience. Participants experienced a heightened feeling of spatial presence and reported increased utilitarian and hedonic value perceptions of the online service experience. We do not find strong support for an alternative, underlying process through psychological ownership. That is, AR's benefits appear to stem from its ability to align with the inherently situated nature of customers' information processing. We next delve deeper into identifying a boundary condition to our findings (H3).

\section{Study 3}

In Study 3 we investigated whether verbalizers derive more value from a feeling of spatial presence than visualizers (H3). In line with previous research (Parasuraman and Grewal 2000), we also sought to provide evidence that customer value perceptions affect post-consumption behavioral intentions. In an online setting, word-of-mouth (WOM) referral is particularly valued as a driver of new customer acquisition (Wangenheim and Bayón 2007). Moreover, self-reported purchase intentions help approximate actual bottom-line sales (Taylor et al. 1975). To test our predictions, we made use of the Mister Spex AR virtual mirror for eyewear with the same manipulations used in Study 1.

\section{Design and procedure}

We used the experimental procedure and manipulations from Study 1 . The between-subjects design also was the same 2 (low versus high SPC) $\times 2$ (low versus high EE) as in our previous studies. The 359 participants, aged between 16 and 25 years, fit the description of digital natives and completed the study in exchange for university course credit. We omitted participants from further analysis if they did not try out the application (11), experienced technical difficulties (7), indicated they did not understand the instructions (7), or provided incomplete responses (6). We also removed six univariate $(1.7 \%)$ and one multivariate $(0.3 \%)$ outliers. The final sample consisted of 321 participants (174 women, $147 \mathrm{men}$ ).

\section{Measures}

We measured utilitarian value $(\alpha=.89)$, hedonic value ( $\alpha=.85)$, and spatial presence $(\alpha=.90)$ with the item batteries and scales from our previous studies. We sought to substantiate the mediating role of spatial presence, by ruling out the possibility that participants provided with SPC and EE simply felt more involved with the application and thus reported perceptions of greater value. Previous research has suggested that involvement is a prerequisite for spatial presence (Wirth et al. 2007) but constitutes a conceptually distinct construct (Schubert et al. 2001). We therefore controlled for participants' involvement in trying out the application with a fouritem involvement measure $(\alpha=.73)$ developed by Vorderer et al. (2004). We assessed participants' disposition toward visual versus verbal information processing with the 22 -item style-of-processing scale $(\alpha=.65)$ developed by Childers et al. (1985). Participants responded to all style-of-processing items on a four-point scale ("always true" to "always false"). High 
values correspond to a visualizer disposition, and a low score implies a verbalizer disposition. Finally, we asked participants to rate their WOM intentions $(\alpha=.81)$ with three items and their purchase intentions $(r=.52)$ with two items (Zeithaml et al. 1996), using five-point Likert scales ("strongly disagree" $=1$ to "strongly agree" $=5$ ). The items for all constructs are in Appendix A.

\section{Results}

Manipulation checks Both manipulations were successful. In the high SPC condition, participants perceived significantly greater SPC than in the low SPC condition $\left(\mathrm{M}_{\mathrm{HighSPC}}=4.49\right.$, $\left.\mathrm{M}_{\text {LowSPC }}=2.56, \mathrm{t}(247)=-18.04, p<.001\right)$. Participants in the high $\mathrm{EE}$ condition indicated significantly greater $\mathrm{EE}$ than those in the low EE condition $\left(\mathrm{M}_{\mathrm{HighEE}}=3.94, \mathrm{M}_{\mathrm{LowEE}}=2.24\right.$, $\mathrm{t}(317)=-15.04, p<.001)$.

Moderated mediation analysis The regression results for this study are in Table 4 . The analysis revealed significant effects of the SPC $\times \mathrm{EE}$ interaction $(\beta=.98, p<.001)$ and involvement $(\beta=.22, p<.001)$ on spatial presence. In partial support of $\mathrm{H} 1$, we found a negative effect of the style-of-processing $\times$ spatial presence interaction on utilitarian value $(\beta=-.46$, $p=.034)$, after controlling for involvement $(\beta=.19$, $p=.003$ ). This interaction effect did not emerge with regard to hedonic value. To test for conditional effects with both firstand second-stage moderation, we employed the PROCESS macro by Hayes (2013, Model 22) and bootstrapped with 5000 draws. An investigation of the conditional indirect effects further supported H3 for utilitarian value. Consistent with our previous studies, we found a significant indirect effect of SPC through spatial presence, but only for the high EE condition (Table 5). We analyzed this conditional indirect effect at three style-of-processing values: the mean (2.59), one standard deviation below the mean (2.32), and one standard deviation above the mean (2.86). The bootstrap CIs indicated significant effects at all three levels, though it grew weaker at higher style-of-processing values (Table 5). We obtained the same pattern of results for the conditional indirect effects of EE (Table 5), in support of our conjecture that verbalizers (versus visualizers) derive more (versus less) utilitarian value from spatial presence arising from both SPC and EE.

WOM and purchase intentions We used the PROCESS macro (Hayes 2013, Model 6) to test whether spatial presence, followed by utilitarian and hedonic value, sequentially mediated the effects of the SPC $\times$ EE interaction on WOM and purchase intentions. We found a significant indirect path through $\mathrm{SPC} \times \mathrm{EE} \rightarrow$ spatial presence $\rightarrow$ utilitarian value $\rightarrow$ WOM $(\beta=.16,95 \% \mathrm{CI}=.10$ to .25$)$ and purchase intentions $(\beta=.13,95 \% \mathrm{CI}=.07$ to .21$)$, as well as through $\mathrm{SPC} \times \mathrm{EE}$ $\rightarrow$ spatial presence $\rightarrow$ hedonic value $\rightarrow$ WOM $(\beta=.13,95 \%$ $\mathrm{CI}=.08$ to .22$)$ and purchase intentions $(\beta=.10,95 \% \mathrm{CI}=.05$ to .18), after controlling for SPC, EE, style-of-processing, and involvement. Thus, we find support for our conjecture that positive behavioral intentions arise from the increased utilitarian and hedonic value perceptions of an AR-enhanced online service experience.

\section{Discussion}

The results of Study 3 reconfirm that a compelling situated experience, in the form of spatial presence and resulting
Table 4 Study 3 regression results

\begin{tabular}{llll}
\hline Independent variables & Spatial presence & Utilitarian value & Hedonic value \\
\hline Constant & $1.81^{* *}$ & -1.00 & $2.81^{*}$ \\
& $(.19)$ & $(1.46)$ & $(1.16)$ \\
Simulated physical control & -.13 & $.34^{* *}$ & -.18 \\
& $(.11)$ & $(.13)$ & $(.10)$ \\
Environmental embedding & $-.40^{* *}$ & -.19 & -.16 \\
& $(.11)$ & $(.13)$ & $(.10)$ \\
Simulated physical control $\times$ environmental embedding & $.98^{* *}$ & -.23 & $.42^{* *}$ \\
& $(.16)$ & $(.19)$ & $(.15)$ \\
Spatial presence & -- & $1.61^{* *}$ & .18 \\
& & $(.56)$ & $(.44)$ \\
Style-of-processing & -- & $1.20^{*}$ & -.17 \\
Style-of-processing $\times$ spatial presence & & $. .56)$ & $(.44)$ \\
& -- & $-.46^{*}$ & .07 \\
Involvement & & $(.22)$ & $(.17)$ \\
& $.22^{* *}$ & $.19^{* *}$ & $.13^{*}$ \\
$\mathrm{R}^{2}$ & $(.06)$ & $(.06)$ & $(.05)$ \\
MSE & .21 & .24 & .26 \\
$\mathrm{~F}$ & .51 & .64 & .40 \\
Df & $21.60^{* *}$ & $13.97^{* *}$ & $15.82^{* *}$ \\
\end{tabular}


Table 5 Study 3 moderated mediation analysis results

Utilitarian value Hedonic value

Conditional indirect effect (IE) of simulated physical control for

\begin{tabular}{|c|c|c|c|c|c|c|c|c|c|}
\hline \multirow{4}{*}{ Low environmental embedding } & Style-of-processing & Boot IE & Boot SE & $95 \%$ LCI & $95 \%$ UCI & Boot IE & Boot SE & $95 \%$ LCI & $95 \%$ UCI \\
\hline & 2.32 & -.07 & .06 & -.19 & .04 & -.04 & .04 & -.13 & .02 \\
\hline & 2.59 & -.05 & .05 & -.15 & .03 & -.05 & .04 & -.14 & .03 \\
\hline & 2.86 & -.04 & .04 & -.13 & .02 & -.05 & .05 & -.15 & .03 \\
\hline \multirow[t]{3}{*}{ High environmental embedding } & 2.32 & .45 & .09 & .29 & .64 & .29 & .07 & .16 & .44 \\
\hline & 2.59 & .34 & .07 & .21 & .50 & .30 & .06 & .19 & .43 \\
\hline & 2.86 & .24 & .09 & .07 & .42 & .32 & .08 & .18 & .48 \\
\hline
\end{tabular}

Conditional indirect effect (IE) of environmental embedding for

\begin{tabular}{llllllllll} 
& Style-of-processing & Boot IE & Boot SE & $95 \%$ LCI & $95 \%$ UCI & Boot IE & Boot SE & $95 \%$ LCI & $95 \%$ UCI \\
Low simulated physical control & 2.32 & -.21 & .06 & -.36 & -.11 & -.14 & .05 & -.24 & -.06 \\
& 2.59 & -.16 & .05 & -.28 & -.08 & -.14 & .04 & -.24 & -.07 \\
& 2.86 & -.11 & .05 & -.23 & -.03 & -.15 & .05 & -.27 & -.07 \\
High simulated physical control & 2.32 & .30 & .08 & .17 & .47 & .19 & .06 & .10 & .33 \\
& 2.59 & .23 & .06 & .13 & .37 & .20 & .05 & .11 & .32 \\
& 2.86 & .16 & .07 & .05 & .31 & .21 & .07 & .10 & .35 \\
\hline
\end{tabular}

The numbers in parentheses are standard errors. Unstandardized coefficients are shown. Significance based on two-tailed test.

$* * p<.01$. $* p<.05$

customer value perceptions of the online service experience, is driven by an interaction effect of SPC and EE. In support of $\mathrm{H} 3$, customers with a disposition toward verbal (versus visual) information processing derive greater utilitarian value from AR-induced spatial presence. Finally, our results indicate that enhanced value perceptions of AR-based service augmentation translate into marketing-relevant behavioral responses in the form of WOM and purchase intentions.

\section{Study 4}

\section{Design and procedure}

With Study 4, we investigated H4, regarding the positive relationship between spatial presence and decision comfort, and $\mathrm{H} 5$, pertaining to the potential attenuation of this relationship by customers' concerns about their awareness of privacy practices. We also sought evidence that increased decision comfort results in positive behavioral intentions (Parker et al. 2016). We employed a survey method in which participants faced an online decision making situation; they were tasked with accessing an online store, exploring the available options, and choosing a pair of sunglasses they would purchase. All participants used the AR virtual mirror for eyewear from Study 1 to make a decision. To focus on the decision making effects and concerns about awareness of privacy practices related to AR-based service augmentation, we did not manipulate SPC or EE as in our previous studies. All participants were thus able to see the glasses on their face in real time (high EE) and control the presentation with head movements (high SPC). Participants were given guidance on how to use the AR virtual mirror, and then used a laptop to explore the site, choose their sunglasses, and subsequently complete our survey. We included the manipulation check questions from the previous studies and established that participants perceived this condition as high SPC and high $\mathrm{EE}\left(\mathrm{M}_{\mathrm{SPC}}=4.04\right.$, $\left.\mathrm{SD}=.55 ; \mathrm{M}_{\mathrm{EE}}=4.08, \mathrm{SD}=.58\right)$. We sampled from the target group for AR and recruited 106 participants between 18 and 29 years of age from an undergraduate business course, then excluded 6 reporting technical difficulties. Participants did not receive any compensation for completing the study. Of the remaining 100 participants, 38 were women and 62 were men.

\section{Measures}

We used the same eight-item spatial presence measure (Vorderer et al. 2004; $\alpha=.93$ ) from our previous studies. For the dependent variable, we used the five-item decision comfort scale (Parker et al. 2016), with questions that referred to the selected sunglasses (e.g., "I am comfortable with choosing these sunglasses"; $\alpha=.89$ ). For the moderator, we used the threeitem scale for the dimension labeled "Awareness of Privacy Practices" (APP) of the Information Privacy Concerns scale (Malhotra et al. 2004). This dimension specifically refers to the "degree to which a (customer) is concerned about his/her awareness of information privacy practices" (Malhotra et al. 2004, p. 339). We slightly adapted the questions to fit the study context (e.g., "Companies using this online try-on tool should disclose the way the personal information and images are collected, processed, and used"); the scale showed good internal consistency $(\alpha=.84)$. Participants also rated their WOM intentions $(\alpha=.85)$ with the three-item measure from Study $3 .{ }^{4}$ All

\footnotetext{
${ }^{4}$ Participants were instructed to choose a pair of sunglasses they would actually purchase, so we only asked them to rate their WOM intentions.
} 
Fig. 3 Study 4: Attenuation of the effect of spatial presence on decision comfort by customers' concerns about their awareness of privacy practices

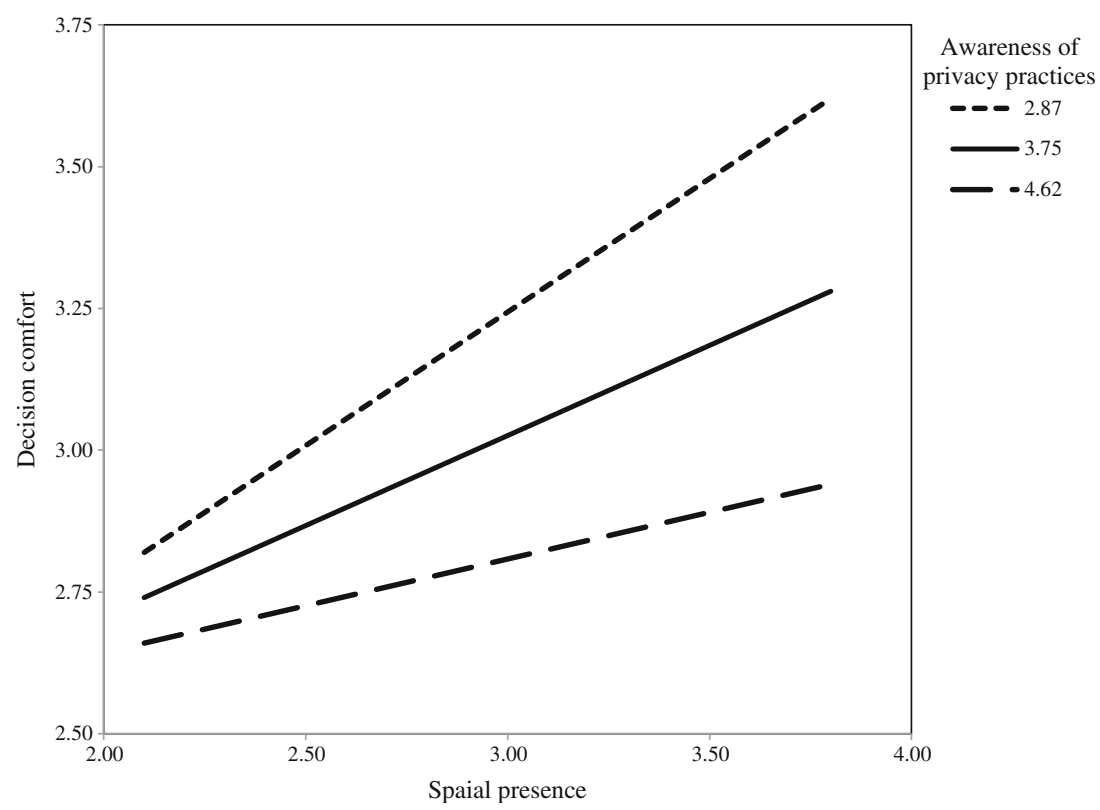

item batteries used five-point Likert scales ("strongly disagree" $=1$ to "strongly agree" = 5), as detailed in Appendix A.

\section{Results}

We first regressed decision comfort on spatial presence $\left(\mathrm{R}^{2}=.26, \mathrm{~F}(1,98)=34.32, p<.001\right)$. In support of $\mathrm{H} 4$, we found a significant positive effect of spatial presence $(\beta=.43$, $\mathrm{t}(98)=5.86, p<.001)$.

Moderation analysis To investigate H5, we regressed decision comfort on spatial presence, awareness of privacy practices, and their interaction $\left(\mathrm{R}^{2}=.39, \mathrm{~F}(3,96)=20.07\right.$, $p<.001)$. In support of $\mathrm{H} 5$, we found a significant negative spatial presence $\times$ awareness of privacy practices interaction effect on decision comfort $(\beta=-.13, \mathrm{t}(96)=-2.14, p=.035)$; spatial presence and awareness of privacy practices, as expected, retained significant positive and negative effects, respectively $\left(\beta_{S P}=.32, \mathrm{t}(96)=4.21, p<.001 ; \beta_{A P P}=-.24\right.$, $\mathrm{t}(96)=-3.18, p=.002)$. For the conditional effects, we bootstrapped with 5000 samples and calculated biascorrected CIs (Hayes 2015). We found positive effects of spatial presence on decision comfort at low $(\beta=.47,95 \%$ $\mathrm{CI}=.28$ to .67$)$ and medium $(\beta=.32,95 \% \mathrm{CI}=.17$ to .45$)$ awareness of privacy practices levels, but not at high levels ( $\beta=.16,95 \% \mathrm{CI}=-.01$ to .33 ). Figure 3 illustrates this gradual attenuation, by customers' concerns about their awareness of privacy practices, on the effect of spatial presence on decision comfort.

WOM intentions We used the PROCESS macro (Hayes 2013, Model 7) and found a positive indirect effect of spatial presence on WOM intentions through decision comfort ( $\beta=.05,95 \% \mathrm{CI}=.00$ to .13$)$ at the mean value of awareness of privacy practices. This finding supports our conjecture that the decision comfort provided by AR-based service augmentation translates into positive behavioral intentions.

\section{General discussion}

By providing a novel, context-sensitive interface for customers to interact with the online organizational frontline, AR offers firms the means to pursue an innovative service augmentation strategy. Against the backdrop of situated cognition theory, we demonstrate that (utilitarian and hedonic) customer value perceptions of the online service experience are driven by an AR-enabled interaction effect of simulated physical control and environmental embedding (Study 1). This effect is produced by customers' convictions that they are experiencing an authentic situated experience, manifested in a feeling of spatial presence (Study 2). The effect of spatial presence on utilitarian value perceptions is more pronounced for customers who prefer verbal information processing (Study 3). We also find that spatial presence provides customers with greater decision comfort; however this effect is attenuated by customers' concerns about being aware of the privacy practices associated with AR-based service augmentation (Study 4).

\section{Implications for theory}

We contribute to contemporary knowledge on services marketing strategies in three related ways. First, as research interest in technology-empowered frontlines increases (Marinova 
et al. 2017), we advance a situated cognition perspective on the design of the interfaces through which customers interact with firms. By framing customers' cognition as an inseparable coupling of environmental stimuli (i.e., embedding) and physical interaction (i.e., embodiment), we conceive of how value is co-created by the customer and the online service environment. Crucially, AR-based service augmentation integrates the touch-and-feel sensory richness of the physical world with the online marketplace (Brynjolfsson et al. 2013). It thus results in a highly context-sensitive interface that aligns with customers' natural processing of information and offers them effective, enjoyable online service experiences. Accordingly, we contribute to understanding customer empowerment in services experiences (Berry et al. 2010), and particularly how emerging smart technologies, such as AR, empower customers through frontline interactions that co-create value (Marinova et al. 2017).

Second, we establish spatial presence in online service experiences as the mediating mechanism by which AR simulates aspects of service that are traditionally reserved for in-store experiences. We therefore contribute to a growing research stream emphasizing that frontline technologies (ranging from AR to service robots) should be assessed in light of the feelings of presence they elicit within a service experience (Rafaeli et al. 2017; van Doorn et al. 2017). Though we do not find strong support for an alternative mediation by psychological ownership, our findings may point to a more intricate process underlying customers' hedonic value perceptions. It seems that when simulated physical control is complemented with the means to environmentally embed, customers not only derive enjoyment from an authentic situated experience, but also from a sense of ownership of the examined offering. More research is thus needed to identify when the enjoyment benefits of AR-based service augmentation stem from an enhanced service experience and when they are due to customer attachment to a specific offering.

Third, by investigating customer heterogeneity in the context of emerging frontline technologies, we learn why spatial presence created through AR-based service augmentation increases value perceptions and decision comfort for some customers more than others. Previous research indicates that the effectiveness of visual product representations depends on individual preferences for visual versus verbal information processing (Childers et al. 1985; Wyer et al. 2008). Consistent with this finding, our results indicate that verbalizers derive more utilitarian value from spatial presence than visualizers. Accordingly, AR may provide enjoyment benefits to a broad customer audience; however, it would increase the effectiveness of online service experiences more for customers less prone to use visualization skills. In particular, visualizers may rely more on their own mental imagery and thus derive less utilitarian value from AR-based service augmentation. Services research increasingly emphasizes collecting and leveraging customer data to enhance service effectiveness (Marinova et al. 2017); our results reveal an important boundary condition for theory on technology-empowered frontline interactions. In particular, we demonstrate that for customers with relatively strong concerns about being adequately aware of a firm's privacy practices, the effect of spatial presence on decision comfort becomes attenuated.

\section{Strategic implications for service managers}

Traditionally, online channels function to reduce costs and aggregate assortment. Yet, they continue to be perceived as low in service (Verhoef et al. 2007). This research addresses the need to understand online shopping as a service experience and develop more innovative service strategies (Dotzel et al. 2013). Emerging frontline interface technologies, such as AR, enable firms to enhance service experiences and promote value co-creation (Singh et al. 2017). By deploying a strategy of AR-based service augmentation, firms can redefine their interactions with customers at the organizational frontline in several ways.

First, this research introduces AR-based service augmentation as part of a broader services marketing strategy. Challenged by customer estrangement when moving between channels, managers aim to provide customers with a more seamless omnichannel experience. In this effort, AR can help service managers synchronize their online and offline service experiences by enabling customers to virtually embed an offering in a personally relevant environment and feel a sense of physical control. The realtime, virtual enhancement of the physical reality empowers customers to shape their experiences and improve their decision making (Rafaeli et al. 2017). The resulting positive WOM and purchase intentions likely benefit online conversion rates, prevent virtual shopping cart abandonment (Janakiraman et al. 2016), and counter webrooming (i.e., when customers gather information online before buying offline; Verhoef et al. 2015).

Second, AR-based service augmentation provides a lower cost alternative to current product trial services (e.g., sampling, free return policies) and allows customers to develop a feel for offerings in an online environment. This benefit is especially relevant for customer interactions with experiential offerings, such as cosmetics, apparel, or furniture, that get evaluated mainly on the basis of fit and feel characteristics (Rosa et al. 2006). Managers must realize that service augmentation relies on spatial presence; it should be a metric for successful AR-based service augmentation. In this respect, AR outperforms current online service experiences, such as those that offer stand-alone 360-degree product rotation. By convincing customers that they are truly able to try out a product offering, AR provides utilitarian and hedonic value in online service experiences. The two value perceptions are 
complementary, and though their individual importance may differ across customer segments and shopping contexts (Childers et al. 2001), they jointly determine the holistic customer experience.

Third, AR-based service augmentation provides customers with a sense of comfort in the crucial post-decision/pre-outcome decision making stage. Providing service comfort (Spake et al. 2003) and connecting emotionally with customers (Kumar and Pansari 2016) are key managerial concerns. We show that using service augmentation to help customers feel comfortable with a decision, irrespective of its optimality, also promotes positive WOM intentions.

Fourth, we studied two main classes of customers, verbalizers and visualizers, to understand whether customers respond differently to AR-based service augmentation. Although verbalizers derived greater utilitarian value from spatial presence, the visualizers did not respond negatively. Accordingly, AR-based service augmentation may provide greater returns on the investment for a predominantly verbalizer segment, but service personalization (Rust and Huang 2014) would have little advantage over a broad application. We recommend providing customers with an option to self-select, for example, an AR virtual mirror from a firm's online service portfolio to enhance decision making. Moreover, the effects of situationally induced processing styles on customer evaluations may rival those of a chronic disposition (Jiang et al. 2007). Therefore, AR-based service augmentation may prove particularly relevant in contexts where the nature of the offering requires firms to use detailed verbal information (e.g., extensive measurement specifications for furniture, technical information for automobiles).

Fifth, the adoption of new technology is often fraught with pitfalls, so managers should give careful consideration to those aspects of the technology that enhance customer value and those that detract from it. The "shiny new object syndrome" has led prior AR investments, such as Google Glass, to be overwhelmed by customers' privacy concerns. Similarly, we show that high levels of concern about awareness of a firm's privacy practices among customers temper the positive effects of AR technology. Service managers, thus, should ensure a clear and conspicuous disclosure of how AR-based service augmentation makes use of customer information (e.g., informing customers upfront that facial recognition in a virtual mirror only serves fitting purposes and that no images are saved).

\section{Limitations and further research}

This research is subject to several limitations that provide opportunities for further research. To test our predictions with a relevant target group, we focused on digital natives. We consider our findings generalizable, but further research is needed to confirm these findings for other generations. Relatedly, future research could identify further relevant customer traits that may account for variation in the value derived from AR-based service augmentation. For example, customers with a high need-for-touch may especially value simulated physical control over an offering embedded in their immediate environment. Our predictions for the effects of visual and verbal processing style also are based on evaluations of familiar products. Although such familiarity is reasonable in our research setting, additional research could test the effects for highly specialized or newly developed products, for which customers rely less on existing evaluation methods; ARbased service augmentation might even have a more pronounced effect in these settings.

Additional research could investigate the nature of the body movements involved in simulated physical control too. Extant embodiment research emphasizes the influence of (in-) congruence on customers' perceptions (e.g., Elder and Krishna 2012). The (in-) congruence between the physical control naturally elicited by a product (e.g., a cup elicits a grasping motion) and the simulated physical control afforded by AR technology (e.g., a virtual cup cannot be grasped, only moved with a touchscreen) should be modeled to determine the impacts on customer perceptions of the online service experience. Embodied incongruence could be an important boundary condition, beyond privacy concerns.

Although social effects are beyond the scope of this research, they could influence our findings, especially as social media become increasingly integral to customerfirm interactions (Rapp et al. 2013). An extension of our research could explore how AR-based service augmentation can leverage social content to identify further innovations for service strategy. Previous research indicates that the lack of social connectivity is a limiting factor for AR (Javornik 2016a). If customers could share live feeds of their virtual mirrors with others to obtain ratings and reviews, it might set the stage for tests of social connectivity effects. Socially situated cognition (Semin and Smith 2013) and social presence (Schultze 2010) theorizing may serve as valuable conceptual backdrops.

As advances in information technology continue to give rise to new service marketing strategies (Rust and Huang 2014), opportunities for research will increase. This article offers a first step toward a theoretical understanding of AR-based service augmentation as a means to enhance online service experience. We call for a furthering of the research agenda for such technologyenabled service augmentation at the organizational frontline. 


\section{Appendix A}

Table 6 Overview of constructs and measurement items

Construct Items

Hedonic value adapted from Childers et al. (2001)

The online shopping experience with the app makes me feel good.

The online shopping experience with the app is boring. (R)

The online shopping experience with the app is exciting.

The online shopping experience with the app is enjoyable.

Utilitarian value adapted from Childers et al. (2001)

Using the app improves my performance in evaluating the product during online shopping.

I find the app to be useful for online shopping.

Using the app enhances my effectiveness in online shopping.

Functionality adapted from Lin and Hsieh (2011)

I can get my product evaluation done with the online retailer's app in a short time.

The product evaluation process with the online retailer's app is clear.

Using the online retailer's app requires little effort.

I can get my product evaluation done smoothly with the online retailer's app.

Each function of the app is error-free.

Spatial presence adapted from Vorderer et al. (2004)

I felt like the [product] was actually there in the real world.

It was as though the true location of the [product] had shifted into the real world environment.

I felt like the [product] meshed with the real world surroundings.

It seemed as if the [product] actually took part in the action in the real world.

I had the impression that I could be active with the [product] in the real world.

I felt like I could move the [product] around in the real world.

The [product] gave me the feeling I could do things with it.

It seemed to me that I could do whatever I wanted with the [product].

Psychological ownership Peck and Shu (2009)

I feel like this is my [product].

I feel a very high degree of personal ownership of the [product].

I feel like I own this [product].

Style-of-processing Childers et al. (1985)

I enjoy doing work that requires the use of words. (R)

There are some special times in my life that I like to relive by mentally "picturing" just how everything looked.

I can never seem to find the right word when I need it.

I do a lot of reading. (R)

When I'm trying to learn something new, I'd rather watch a demonstration than read how to do it.

I think I often use words in the wrong way.

I enjoy learning new words. (R)

I like to picture how I could fix up my apartment or a room if I could buy anything I wanted.

I often make written notes to myself. (R)

I like to daydream.

I generally prefer to use a diagram rather them a written set of instructions.

I like to "doodle" (i.e., draw pictures or patterns while thinking about something else or when I am bored).

I find it helps to think in terms of mental pictures when doing many things.

After I meet someone for the first time. I can usually remember what they look like, but not much about them.

I like to think of synonyms for words. (R)

When I have forgotten something I frequently try to form a mental "picture" to remember it.

I like learning new words. (R)

I prefer to read instructions about how to do something rather than have someone show me. (R)

I prefer activities that don't require a lot of reading.

I seldom daydream. (R)

I spend very little time attempting to increase my vocabulary.

My thinking often consists of mental "pictures" or images.

Word-of-mouth (WOM) intentions adapted from Zeithaml et al. (1996)

I would say positive things about [the online retailer] to other people.

I would recommend [the online retailer] to someone who seeks my advice.

I would encourage friends and relatives to do business with [the online retailer].

Purchase intentions adapted from Zeithaml et al. (1996)
Table 6 (continued)

Construct Items

I would consider [the online retailer] as one of my first choices to buy [product] online.

I would do more business with [the online retailer] in the next few years.

Involvement Vorderer et al. (2004)

I thought most about things having to do with the web app.

I thoroughly considered what the things in the web app had to do with one another.

The web app activated my thinking.

I thought about whether the web app could be of use to me.

Decision comfort Parker et al. (2016)

I am comfortable with choosing this [product].

I feel good about choosing this [product].

I am experiencing negative emotions about choosing this [product].

Whether or not it is "the best choice," I am okay with choosing this [product].

Although I don't know if this [product] is the best, I feel perfectly comfortable with the choice I made.

Awareness of privacy practices adapted from Malhotra et al. (2004)

Companies using this online try-on tool should disclose the way the personal information and images are collected, processed, and used.

A good consumer online privacy policy to accompany this online try-on tool should have a clear and conspicuous disclosure.

It is very important to me that I am aware and knowledgeable about how my personal information and images will be used.

(R) Reverse-coded item 


\section{Appendix B}

Overview of stimulus materials and manipulations

Studies 1,3 , and 4

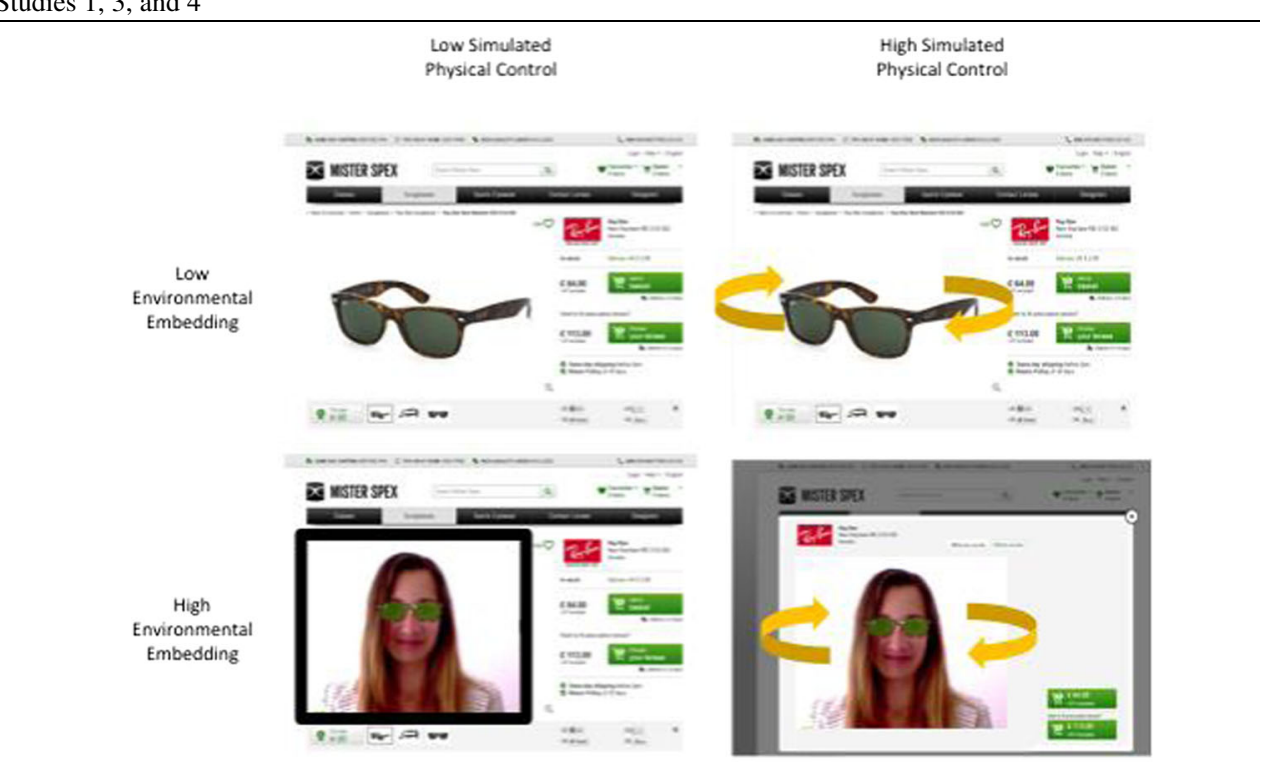

Study 2

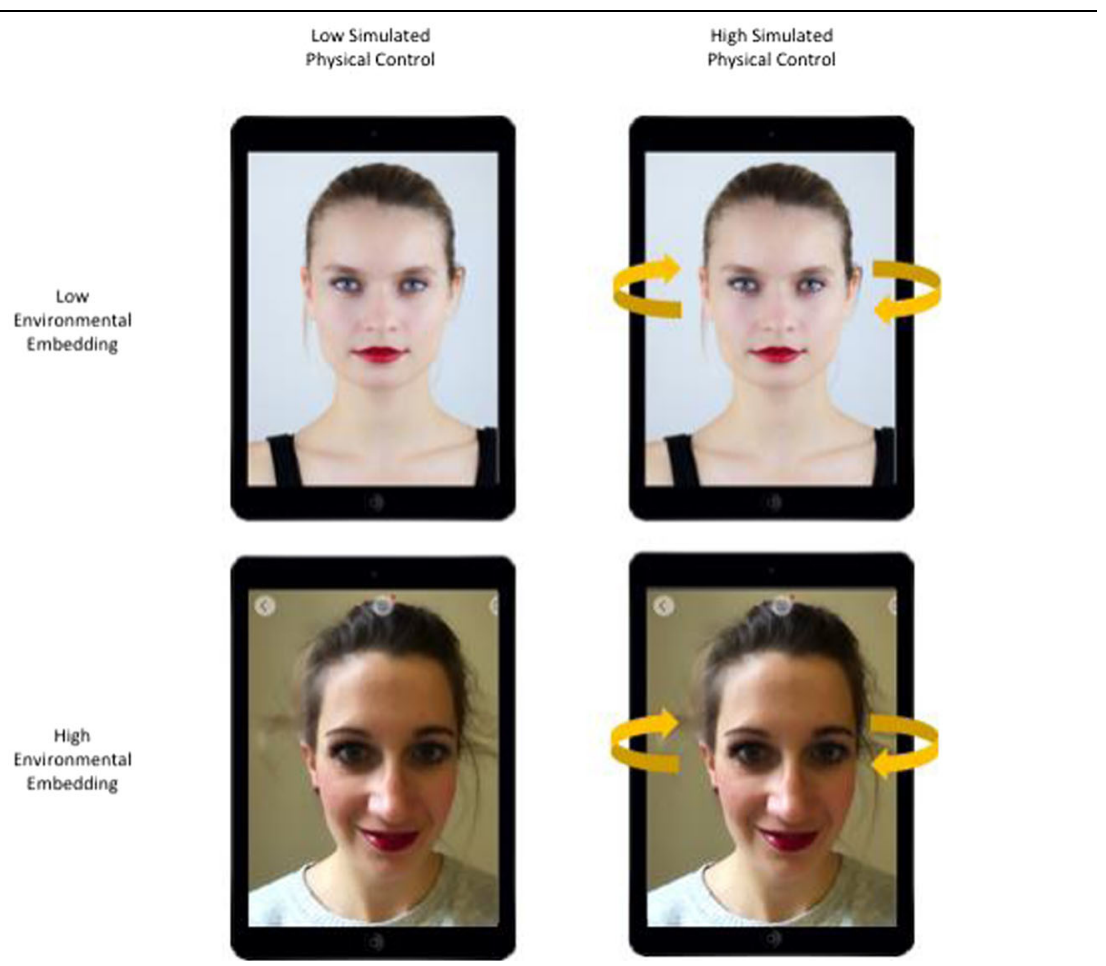


Open Access This article is distributed under the terms of the Creative Commons Attribution 4.0 International License (http:// creativecommons.org/licenses/by/4.0/), which permits unrestricted use, distribution, and reproduction in any medium, provided you give appropriate credit to the original author(s) and the source, provide a link to the Creative Commons license, and indicate if changes were made.

\section{References}

ABI Research. (2013). Developers to invest \$2.5 billion in augmented reality in 2018. Retrieved January 10, 2016 from: https://www. abiresearch.com/press/developers-to-invest-25-billion-inaugmented-reali/.

Azuma, R., Baillot, Y., Behringer, R., Feiner, S., Julier, S., \& MacIntyre, B. (2001). Recent advances in augmented reality. Computer Graphics and Applications, IEEE, 21(6), 34-67.

Babin, B. J., Lee, Y. K., Kim, E. J., \& Griffin, M. (2005). Modeling consumer satisfaction and word-of-mouth: Restaurant patronage in Korea. Journal of Services Marketing, 19(3), 133-139.

Barsalou, L. W. (2008). Grounded cognition. Annual Review of Psychology, 59, 617-645.

Bauer, H. H., Falk, T., \& Hammerschmidt, M. (2006). eTransQual: A transaction process-based approach for capturing service quality in online shopping. Journal of Business Research, 59(7), 866-875.

Beck, M., \& Crié, D. (2016). I virtually try it... I want it! Virtual Fitting Room: A tool to increase on-line and off-line exploratory behavior, patronage and purchase intentions. Journal of Retailing and Consumer Services. Available online 15 October 2016, In press. doi:10.1016/j.jretconser.2016.08.006.

Berry, L. L. (2016). Revisiting "big ideas in services marketing” 30 years later. Journal of Services Marketing, 30(1), 3-6.

Berry, L. L., Bolton, R. N., Bridges, C. H., Meyer, J., Parasuraman, A., \& Seiders, K. (2010). Opportunities for innovation in the delivery of interactive retail services. Journal of Interactive Marketing, 24(2), $155-167$.

Brynjolfsson, E., Hu, Y. J., \& Rahman, M. S. (2013). Competing in the age of omnichannel retailing. MIT Sloan Management Review, 54(4), 23-29.

Cadirci, T. O., \& Kose, S. G. (2016). Augmented reality as a tool to enhance the experiential value of online shopping: The future of fashion retailing. In A. Vecchi (Ed.), Handbook of research on global fashion management and merchandising (pp. 280-304). Hershey: IGI Global.

Carassa, A., Morganti, F., \& Tirassa, M. (2005). A situated cognition perspective on presence. In L. W. Bara \& M. Bucciarelli (Eds.), XXVII annual conference of the cognitive science society (pp. 384-389). Alpha: Sheridan Printing.

Childers, T. L., Houston, M. J., \& Heckler, S. E. (1985). Measurement of individual differences in visual versus verbal information processing. Journal of Consumer Research, 12(2), 125-134.

Childers, T. L., Carr, C. L., Peck, J., \& Carson, S. (2001). Hedonic and utilitarian motivations for online retail shopping behavior. Journal of Retailing, 77(4), 511-535.

Clancey, W. J. (2009). Scientific antecedents of situated cognition. In P. Robbins \& M. Aydede (Eds.), The Cambridge handbook of situated cognition (pp. 11-34). New York: Cambridge University Press.

CNBC. (2016). Apple CEO Tim Cook on virtual reality: 'There's no substitute for human contact'. Retrieved November 16, 2016 from: http://www.cnbc.com/2016/10/14/apple-ceo-tim-cook-on-virtualreality-theres-no-substitute-for-human-contact.html.

Dabholkar, P. A., \& Bagozzi, R. P. (2002). An attitudinal model of technology-based self-service: Moderating effects of consumer traits and situational factors. Journal of the Academy of Marketing Science, 30(3), 184-201.

Dacko, S. G. (2016). Enabling smart retail settings via mobile augmented reality shopping apps. Technological Forecasting and Social Change. Available online 14 October 2016, In press. doi:10.1016/ j.techfore.2016.09.032.

Dotzel, T., Shankar, V., \& Berry, L. L. (2013). Service innovativeness and firm value. Journal of Marketing Research, 50(2), 259-276.

Downes. (2013). What Google Glass reveals about privacy fears. Harvard business review. Retrieved November 6, 2016 from: https://hbr.org/2013/05/what-google-glass-reveals-abou.

Draper, J. V., Kaber, D. B., \& Usher, J. M. (1998). Telepresence. Human Factors, 40, 354-375.

Dunleavy, M., Dede, C., \& Mitchell, R. (2009). Affordances and limitations of immersive participatory augmented reality simulations for teaching and learning. Journal of Science Education and Technology, 18(1), 7-22.

Elder, R. S., \& Krishna, A. (2012). The "visual depiction effect" in advertising: Facilitating embodied mental simulation through product orientation. Journal of Consumer Research, 38(6), 988-1003.

Escalas, J. E. (2004). Imagine yourself in the product: Mental simulation, narrative transportation, and persuasion. Journal of Advertising, $33(2), 37-48$.

Fiore, A. M., Kim, J., \& Lee, H.-H. (2005). Effect of image interactivity technology on consumer responses toward the online retailer. Journal of Interactive Marketing, 19(3), 38-53.

Gartner. (2015). Gartner's 2015 Hype Cycle for emerging technologies identifies the computing innovations that organizations should monitor. Retrieved June 15, 2016 from: http://www.gartner.com/ newsroom $/ \mathrm{id} / 3114217$.

Gibson, J. J. (1979). The ecological approach to visual perception. Boston: Houghton Mifflin.

Grohmann, B., Spangenberg, E. R., \& Sprott, D. E. (2007). The influence of tactile input on the evaluation of retail product offerings. Journal of Retailing, 83(2), 237-245.

Grönroos, C. (1990). Service management and marketing. Lexington: Lexington Books.

Hayes, A. F. (2013). Introduction to mediation, moderation, and conditional process analysis: A regression-based approach. New York: Guilford Press.

Hayes, A. F. (2015). Hacking PROCESS for bootstrap inference in moderation analysis. The Ohio State University: Unpublished white paper.

Hopp, T., \& Gangadharbatla, H. (2016). Novelty effects in augmented reality advertising environments: The influence of exposure time and self-efficacy. Journal of Current Issues \& Research in Advertising, 37(2), 113-130.

Huang, T. L., \& Liao, S. (2015). A model of acceptance of augmentedreality interactive technology: The moderating role of cognitive innovativeness. Electronic Commerce Research, 15(2), 269-295.

ISPR [International Society for Presence Research]. (2000). The concept of presence: Explication statement. Retrieved April 10, 2014 from: https://ispr.info/.

Janakiraman, N., Syrdal, H. A., \& Freling, R. (2016). The effect of return policy leniency on consumer purchase and return decisions: A metaanalytic review. Journal of Retailing, 92(2), 226-235.

Javornik, A. (2016a). Augmented reality: Research agenda for studying the impact of its media characteristics on consumer behaviour. Journal of Retailing and Consumer Services, 30, 252-261.

Javornik, A. (2016b). 'It's an illusion, but it looks real!' consumer affective, cognitive and behavioural responses to augmented reality applications. Journal of Marketing Management, 32(9-10), 987-1011.

Jiang, Y., Steinhart, Y., \& Wyer, R. S. (2007). The role of visual and semantic processing strategies in consumer information processing. Hong Kong University of Science and Technology: Unpublished manuscript. 
Kim, J., \& Forsythe, S. (2008). Sensory enabling technology acceptance model (SE-TAM): A multiple-group structural model comparison. Psychology \& Marketing, 25(9), 901-922.

Klein, L. R. (2003). Creating virtual product experiences: The role of telepresence. Journal of Interactive Marketing, 17(1), 41-55.

Kumar, V., \& Pansari, A. (2016). Competitive advantage through engagement. Journal of Marketing Research, 53(4), 497-514.

Laroche, M., McDougall, G. H., Bergeron, J., \& Yang, Z. (2004). Exploring how intangibility affects perceived risk. Journal of Service Research, 6(4), 373-389.

Lin, J. S. C., \& Hsieh, P. L. (2011). Assessing the self-service technology encounters: Development and validation of SSTQUAL scale. Journal of Retailing, 87(2), 194-206.

Lombard, M., \& Ditton, T. (1997). At the heart of it all: The concept of presence. Journal of Computer-Mediated Communication, 3(2). doi:10.1111/j.1083-6101.1997.tb00072.x.

Lombard, M., \& Snyder-Duch, J. (2001). Interactive advertising and presence: A framework. Journal of Interactive Advertising, 1(2), $56-65$.

Malhotra, N. K., Kim, S. S., \& Agarwal, J. (2004). Internet users' information privacy concerns (IUIPC): The construct, the scale, and a causal model. Information Systems Research, 15(4), 336-355.

Marinova, D., de Ruyter, K., Huang, M. H., Meuter, M. L., \& Challagalla, G. (2017). Getting smart: Learning from technology-empowered frontline interactions. Journal of Service Research, 20(1), 29-42.

Martin, K. D., Borah, A., \& Palmatier, R. W. (2017). Data privacy: Effects on customer and firm performance. Journal of Marketing, 81(1), 36-58

McDowell, W. C., Wilson, R. C., \& Kile, C. O. (2016). An examination of retail website design and conversion rate. Journal of Business Research., 69(11), 4837-4842.

McKone, D., Haslehurst, R., \& Steingoltz, M. (2016). Virtual and augmented reality will reshape retail. In Harvard business review Retrieved November 17, 2016 from: https://hbr.org/2016/09/ virtual-and-augmented-reality-will-reshape-retail.

Milgram, P., \& Kishino, F. (1994). A taxonomy of mixed reality visual displays. IEICE Transactions on Information and Systems, 77(12), 1321-1329.

Niedenthal, P. M. (2007). Embodying emotion. Science, 316(5827), $1002-1005$

Nielsen. (2014). Nielsen global E-Commerce report August 2014. Retrieved June 15, 2016 from: http://s1.q4cdn.com/199638165/ files/doc_financials/Nielsen-Global-E-commerce-Report-August2014.pdf.

Nielsen. (2015). Digital natives feel right at home with online grocery shopping. Retrieved June 15, 2016 from: http://www.nielsen.com/ ie/en/insights/news/2015/digital-natives-feel-right-at-home-withonline-grocery-shopping.html.

Olsson, T., Lagerstam, E., Kärkkäinen, T., \& Väänänen-Vainio-Mattila, K. (2013). Expected user experience of mobile augmented reality services: A user study in the context of shopping centres. Personal and Ubiquitous Computing, 17(2), 287-304.

Parasuraman, A., \& Grewal, D. (2000). The impact of technology on the quality-value loyalty chain: A research agenda. Journal of the Academy of Marketing Science, 28(1), 168-174.

Parker, J. R., Lehmann, D. R., \& Xie, Y. (2016). Decision comfort. Journal of Consumer Research, 43(1), 113-133.

Peck, J., \& Shu, S. B. (2009). The effect of mere touch on perceived ownership. Journal of Consumer Research, 36(3), 434-447.

Pierce, J. L., Kostova, T., \& Dirks, K. T. (2003). The state of psychological ownership: Integrating and extending a century of research. Review of General Psychology, 7(1), 84-107.

Poncin, I., \& Mimoun, M. S. B. (2014). The impact of "e-atmospherics" on physical stores. Journal of Retailing and Consumer Services, 21(5), 851-859.
Poushneh, A., \& Vasquez-Parraga, A. Z. (2017). Discernible impact of augmented reality on retail customer's experience, satisfaction and willingness to buy. Journal of Retailing and Consumer Services, 34 , 229-234.

Rafaeli, A., Altman, D., Gremler, D. D., Huang, M. H., Grewal, D., Iyer, B., Parasuraman, A., \& de Ruyter, K. (2017). The future of frontline research. Journal of Service Research, 20(1), 91-99.

Rapp, A., Skinner Beitelspacher, L., Grewal, D., \& Hughes, D. E. (2013). Understanding social media effects across seller, retailer, and consumer interactions. Journal of the Academy of Marketing Science, 41(5), 547-566.

Rese, A., Schreiber, S., \& Baier, D. (2014). Technology acceptance modeling of augmented reality at the point of sale: Can surveys be replaced by an analysis of online reviews? Journal of Retailing and Consumer Services, 21(5), 869-876.

Rese, A., Baier, D., Geyer-Schulz, A., \& Schreiber, S. (2016). How augmented reality apps are accepted by consumers: A comparative analysis using scales and opinions. Technological Forecasting and Social Change. Available online 30 October 2016, In press. doi:10. 1016/j.techfore.2016.10.010.

Riva, G., Baños, R. M., Botella, C., Mantovani, F., \& Gaggioli, A. (2016). Transforming experience: The potential of augmented reality and virtual reality for enhancing personal and clinical change. Frontiers in Psychiatry, 7, 164.

Robbins, P., \& Aydede, M. (2009). A short primer on situated cognition. In P. Robbins \& M. Aydede (Eds.), The Cambridge handbook of situated cognition (pp. 3-10). New York: Cambridge University Press.

Rosa, J. A., \& Malter, A. J. (2003). E-(embodied) knowledge and ecommerce: How physiological factors affect online sales of experiential products. Journal of Consumer Psychology, 13(1-2), 63-73.

Rosa, J. A., Garbarino, E. C., \& Malter, A. J. (2006). Keeping the body in mind: The influence of body esteem and body boundary aberration on consumer beliefs and purchase intentions. Journal of Consumer Psychology, 16(1), 79-91.

Rust, R. T., \& Huang, M. H. (2014). The service revolution and the transformation of marketing science. Marketing Science, 33(2), 206-221.

Sanchez-Vives, M. V., \& Slater, M. (2005). From presence to consciousness through virtual reality. Nature Reviews Neuroscience, 6(4), 332-339.

Schubert, T. W. (2009). A new conception of spatial presence: Once again, with feeling. Communication Theory, 19(2), 161-187.

Schubert, T., Friedmann, F., \& Regenbrecht, H. (2001). The experience of presence: Factor analytic insights. Presence, 10(3), 266-281.

Schultze, U. (2010). Embodiment and presence in virtual worlds: A review. Journal of Information Technology, 25(4), 434-449.

Semin, G. R., \& Smith, E. R. (2013). Socially situated cognition in perspective. Social Cognition, 31(2), 125-146.

Singh, J., Brady, M., Arnold, T., \& Brown, T. (2017). The emergent field of organizational frontlines. Journal of Service Research, 20(1), 3 11.

Spake, D. F., Beatty, S. E., Brockman, B. K., \& Crutchfield, T. N. (2003). Consumer comfort in service relationships measurement and importance. Journal of Service Research, 5(4), 316-332.

Spreer, P., \& Kallweit, K. (2014). Augmented reality in retail: Assessing the acceptance and potential for multimedia product presentation at the PoS. Transactions on Marketing Research, 1(1), 20-35.

Stevens, B., Jerrams-Smith, J., Heathcote, D., \& Callear, D. (2002). Putting the virtual into reality: Assessing object-presence with projection-augmented models. Presence: Teleoperators and Virtual Environments, 11(1), 79-92.

Taylor, J. W., Houlahan, J. J., \& Gabriel, A. C. (1975). The purchase intention question in new product development: A field test. Journal of Marketing, 39(1), 90-92. 
Tsai, J. Y., Egelman, S., Cranor, L., \& Acquisti, A. (2011). The effect of online privacy information on purchasing behavior: An experimental study. Information Systems Research, 22(2), 254-268.

van Doorn, J., Mende, M., Noble, S. M., Hulland, J., Ostrom, A. L., Grewal, D., \& Petersen, J. A. (2017). Domo arigato Mr. Roboto: Emergence of automated social presence in organizational frontlines and customers' service experiences. Journal of Service Research, 20(1), 43-58.

Verhoef, P. C., Neslin, S. A., \& Vroomen, B. (2007). Multichannel customer management: Understanding the research-shopper phenomenon. International Journal of Research in Marketing, 24(2), 129148.

Verhoef, P. C., Kannan, P. K., \& Inman, J. J. (2015). From multichannel retailing to omni-channel retailing: Introduction to the special issue on multi-channel retailing. Journal of Retailing, 91(2), 174-181.

Vorderer, P, Wirth, W., Gouveia, F. R., Biocca, F., Saari, T., Jäncke, F., Böcking, S., Schramm, H., Gysbers, A., Hartmann, T., Klimmt, C., Laarni, J., Ravaja, N., Sacau, A., Baumgartner, T. \& Jäncke, P. (2004). MEC spatial presence questionnaire (MECSPQ): Short documentation and instructions for application. Report to the European Community, project presence: MEC (IST-2001-37661). Online Available from: http://www.ijk.hmt-hannover.de/presence.

Wangenheim, F. V., \& Bayón, T. (2007). The chain from customer satisfaction via word-of-mouth referrals to new customer acquisition. Journal of the Academy of Marketing Science, 35(2), 233-249.

Weibel, D., Wissmath, B., \& Mast, F. W. (2011). Influence of mental imagery on spatial presence and enjoyment assessed in different types of media. Cyberpsychology, Behavior, and Social Networking, 14(10), 607-612.

Wilson, M. (2002). Six views of embodied cognition. Psychonomic Bulletin \& Review, 9(4), 625-636.

Winkielman, P., Schwarz, N., Fazendeiro, T. A., \& Reber, R. (2003). The hedonic marking of processing fluency: Implications for evaluative judgment. In J. Musch \& K. C. Klauer (Eds.), The psychology of evaluation: Affective processes in cognition and emotion (pp. 189217). Mahwah: Erlbaum.

Wirth, W., Hartmann, T., Böcking, S., Vorderer, P., Klimmt, C., Schramm, H., et al. (2007). A process model of the formation of spatial presence experiences. Media Psychology, 9(3), 493-525.

Wirth, W., Hofer, M., \& Schramm, H. (2012). The role of emotional involvement and trait absorption in the formation of spatial presence. Media Psychology, 15(1), 19-43.

Wyer, R. S., Hung, I. W., \& Jiang, Y. (2008). Visual and verbal processing strategies in comprehension and judgment. Journal of Consumer Psychology, 4(18), 244-257.

Yaoyuneyong, G., Foster, J., Johnson, E., \& Johnson, D. (2016). Augmented reality marketing: Consumer preferences and attitudes toward hypermedia print ads. Journal of Interactive Advertising, 16(1), 16-30.

Zeithaml, V. A., Berry, L. L., \& Parasuraman, A. (1996). The behavioral consequences of service quality. Journal of Marketing, 60(2), 31-46.

Zhu, Z., Nakata, C., Sivakumar, K., \& Grewal, D. (2007). Self-service technology effectiveness: The role of design features and individual traits. Journal of the Academy of Marketing Science, 35(4), 492506. 